This document is the accepted manuscript version of the following article:

Haas, M., Kaltenrieder, P., Ladd, S. N., Welte, C., Strasser, M., Eglinton, T. I., \& Dubois, N. (2020). Land-use evolution in the catchment of Lake Murten, Switzerland. Quaternary Science Reviews, 230, 106154 (12 pp.).

https://doi.org/10.1016/j.quascirev.2019.106154

\title{
Land-use evolution in the catchment of Lake Murten,
}

\section{Switzerland}

Mischa Haas ${ }^{1,2}$ Petra Kaltenrieder ${ }^{3,4}$, S. Nemiah Ladd ${ }^{1,2}$, Caroline Welte ${ }^{5}$, Michael Strasser 6 ,

${ }^{1}$ Swiss Federal Institute of Aquatic Science and Technology (Eawag), CH-8600 Dübendorf

${ }^{2}$ Department of Earth Sciences, ETH Zürich, CH-8006 Zürich

${ }^{3}$ Institute of Plant Sciences, University of Bern, CH-3012 Bern

${ }^{4}$ Oeschger Center for Climate Change Research, University of Bern, CH-3012 Bern

${ }^{5}$ Laboratory of Ion Beam Physics, ETH Zürich, CH-8006 Zürich

${ }^{6}$ Department of Geology, Universität Innsbruck, AT-6020 Innsbruck

Corresponding Author: mischa.haas@eawag.ch

\section{Highlights:}

- Pollen and leaf waxes from Lake Murten record land-use evolution since prehistory

- Large-scale Roman deforestation and farming around the city of Aventicum

- Land-use and vegetation recovery times following Roman disturbance took centuries

Anthropogenic soil erosion is a problem of global concern and recently has become the focus of extensive research. In spite of this, our knowledge about the history of land-use and its long-term impact on soil erosion and the local environment remains limited. This study seeks to address this issue by investigating sediments of Lake Murten, Switzerland, using a multi-proxy approach to reconstruct the history of land-use and its impacts in the catchment. We analyzed pollen and charcoal to reconstruct past land-use and vegetation dynamics, and used the distributions of terrestrial leaf wax biomarkers, their $\delta^{13} \mathrm{C}$ isotopic composition and their soil retention time (compound-specific ${ }^{14} \mathrm{C}$ ) to evaluate long-term effects on past soil carbon dynamics. 
27 Arboreal pollen abundances, charcoal influx and cultural indicators match the archaeological evidence and 28 reveal an eventful past around the lake. The first signs of human presence were detected around $5000 \mathrm{BCE}$, 29 when Neolithic pile dwellers occupied the lake's shores. However, human land-use had no significant effect on the pollen and the sedimentary organic matter (OM) composition during Neolithic times and the Bronze Age. This changed during the Late Iron Age and the Early Roman Period (ca. 70 BCE). Coincident with the rise of Aventicum, a Roman city, large-scale deforestation and agriculture began in the region. Severe soil degradation and outwash of soil organic carbon (SOC) at this time is documented by enhanced input of soilderived and pre-aged leaf waxes, and resulted in cultural eutrophication ca. 2000 years ago. Soil erosion decreased after the fall of the Roman Empire and a short period of renaturation followed. Although the export of SOC returned to pre-Roman values after ca. 200 years, the forest never recovered to its past extent. The last two detected periods of land-use change correlate with the onset of Medieval agriculture (ca. $1000 \mathrm{CE}$ ) and the Industrial Period (ca. $1800 \mathrm{CE}$ ). Today, the mean transit time of leaf waxes is almost five times longer compared to the Roman Period, suggesting that substantial soil erosion has occurred and that an even longer time period would be necessary for the soil carbon dynamics to recover to their natural state.

Key words: Land-use Reconstruction, Pollen, Charcoal, Leaf Waxes, Compound-Specific $\delta^{13} \mathrm{C}$, Compound-Specific Radiocarbon Dating

\section{Introduction}

47 Soil erosion as a consequence of human land-use is a pervasive problem of global concern (Lal, 2004;

48 Quinton et al., 2010). Land-clearing, field cultivation and pastoralism are considered to be the land-use 49 activities that are the most influential drivers of soil erosion. Such landscape modifying activities do not only

50 have direct physical impacts on soils, but also have indirect impacts, including changes in local carbon 51 dynamics (Foster et al., 2003). Soil organic carbon (SOC) is the largest terrestrial carbon reservoir on Earth 52 (Quinton et al., 2010) and the magnitude of the changes in local carbon dynamics due to the mobilization, transport and redistribution of SOC has been much-debated in the context of land-use change (Lal, 2005; Van Oost et al., 2007). In particular, our knowledge of the long-term impact of soil degradation and its historical 
evolution is rather limited. Past land-use and its legacy can influence terrestrial and aquatic ecosystems,

56 including ecological functions, for centuries or even longer (Foster et al., 2003). Analyzing soil erosion rates

57 in a historical to pre-historical context allows pre-anthropogenic conditions, the long-term influence of intensive land-use periods and the effects of renaturation periods to be evaluated.

60 Sedimentary repositories are promising archives that can be used to improve our understanding of the

61 relationship between land-use history and SOC dynamics. Terrestrial archives integrating a catchment wide signal, such as lake or peat sediments, are natural recorders of environmental change and can be used to study soil erosion in a historical perspective (Huang and O'Connell, 2000). During phases of human land-use, i.e. activities that modify landscapes, the structure of top- and subsoil gets destroyed (Lal, 2002). As a consequence minerogenic and chemical erosional products from the impacted catchment soils, including SOC, are mobilized and often compiled in sedimentary repositories such as lakes (Edwards and Whittington, 2001). Previous studies have documented that organic matter (OM) and specific organic fractions deposited during land-use periods differ significantly in their bulk geochemical properties and in their isotopic composition compared to the material deposited as background sedimentation during undisturbed periods (Enters et al., 2006; Meyers, 1994). However, sedimentary OC is very heterogeneous and contains carbon from diverse allochthonous and autochthonous sources of both geological and biological origin (Gierga et al., 2016), which dilutes the initial SOC signal and can make it difficult to identify periods of land-use change from the properties of bulk soil alone.

In the last decades, new attempts to address the complications regarding the heterogeneity of sedimentary OC have been developed with a focus on source-specific organic compound classes of terrestrial origin (Douglas et al., 2018; Galy et al., 2011). In general, only a low percentage of eroded terrestrial OC is permanently buried in the sedimentary record due to early diagenesis and microbial consumption during transit and initial deposition (Vonk et al., 2010). This leads to the selective preservation of organic compounds with relatively recalcitrant molecular structures and affiliation to mineral matrices (Vonk et al., 2010). Among the compounds that are particularly well preserved in sediments, leaf wax lipids that are predominantly produced by higher terrestrial plants are among the most studied. These long-chain $n$-alkanes and $n$-carboxylic acids 
83 have a persistent molecular structure and are well-represented in the refractory SOC pool (Douglas et al., 84 2018; Feng et al., 2013; Smittenberg et al., 2006).

By analyzing leaf wax molecular distributions, isotopic compositions and relative ages, it is possible to gain specific information not only about the paleoenvironment that prevailed during the time of synthesis but also about their past (and current) retention times in soils (Douglas et al., 2018; Dubois and Jacob, 2016). In recent studies, compound-specific radiocarbon analyses (CSRA) of leaf waxes from lake sediments has confirmed that periods of land-use have long-lasting effects on soil carbon dynamics (Douglas et al., 2018, 2014; Gierga et al., 2016). In these studies, the relative retention or transit time of leaf waxes provided an estimate of soil stability through time. However, in order to clearly identify anthropogenic effects and to exclude natural background erosion, additional independent proxies, such as the study of pollen and non-pollen palynomorphs, can provide important environmental context.

Pollen, spores and non-pollen palynomorphs retrieved from lake sediment are frequently used to estimate relative changes in vegetation cover within the catchment or to identify land-use periods. Palynological proxies have emerged as a robust tool to trace paleoecological changes (Bichet et al., 2013; Hillbrand et al., 2014; Tinner et al., 2003). Periods of human land-use are often associated with significant increases in the charcoal influx due to fire activity and with the occurrence of a variety of cultural indicator species, such as Cerealia type and Plantago lanceolata pollen or spores of coprophilous fungi (Behre, 1988; Cugny et al., 2010; Tinner et al., 2003; van Geel et al., 2003).

In a previous publication we detected drastic increases in soil erosion indicators correlating with the timing of Roman land-use 2000 years ago and the Industrial Period (Haas et al., 2019). Building on this framework, we applied in the current study a more source-specific approach based on pollen and leaf wax data in order to reconstruct the evolution of land-use and its impact on soil degradation in the catchment of Lake Murten, for the past 8000 years.

109 First, we analyzed the distribution of pollen in the sedimentary record to develop an overview of the regional 110 to local vegetation history, to identify human activities, and to assess paleoecological changes triggered by 
111 human land-use. Second, we estimated the influence of human land-use on local carbon dynamics in a pre-

112 historical to historical context, using the distribution, isotopic composition $\left(\delta^{13} \mathrm{C}\right.$ values $)$ and relative ages

113 (CSRA) of terrestrial leaf waxes. This allowed us to evaluate not only the long-term influence of intensive

114 land-use periods on soil degradation, but also to investigate pre-anthropogenic conditions and effects of

115 renaturation periods on the local carbon dynamics.

\section{1.1. Study Site}

118 Lake Murten is situated in the lowlands of western Switzerland, also known as the Swiss Plateau region

119 (Figure 1). The catchment has - geologically spoken - a relatively mixed bedrock composition, with various 120 conglomerates, sandstones, clays and marls (Pfiffner, 2014). The hillsides, such as Mont Vully, are glacially 121 imprinted side moraines. Towards the south of the lake lies the alluvial plain of the La Broye river, 122 representing the main inflow to the lake.

124 Figure 1: Location of Lake Murten (Switzerland). Locations of human settlements around the lake from the 125 Neolithic to the Medieval Period are indicated by the colored regions, and gray shading represents local 126 topography (Castella et al., 2015; Nast, 2006; UNESCO Palafittes, 2015). Data source: swisstopo (Art. 30 127 GeoIV): 5704000000 / swissTLM3D@2011, DHM25@2003, Vector200@2011, reproduced with permission 128 of swisstopo / JA100119.

130 The Swiss Plateau region is rich in archaeological sites from several periods of human activity. The shores of 131 Lake Murten have a remarkably dense history of settlement and cultural activities (Figure 1). Beginning 7000 $132-6000$ years ago, Neolithic pile dweller communities lived by Lake Murten (Menotti, 2004; UNESCO 133 Palafittes, 2015) and their sedentary lifestyle dominated the shores of the lake for millennia. In the Late Iron 134 Age (La Tène cultural period, 450 - 20 BCE), large-scale deforestation and farming first occurred in the catchment area as the population became more dense and centralized. Architectural remnants of this Celtic era include the remains of a fortress (lat. oppidum) on Mont Vully, overlooking the area of Lake Murten and Lake Neuchâtel (Nast, 2006) (Figure 1). 
139 The Romans made their entrance to the Swiss Plateau in the $1^{\text {st }}$ century before the Common Era (BCE).

140 Numerous ruins and excavations in and around the village of Avenches provide evidence of an influential

141 Roman city called Aventicum, capital of the Helvetians, within close proximity to the lake. At the peak of its 142 influence ( $2^{\text {nd }}$ century common era, CE) Aventicum contained approximately 20,000 inhabitants, which led to 143 further large-scale deforestation and agriculture in the region (Castella et al., 2015). After the fall of the 144 Roman Empire ( $5^{\text {th }}$ century CE), the Great Migration Period led to socio-economic changes that contributed to 145 a decentralization of the population. Archaeological findings from this period are rare in the vicinity of Lake 146 Murten.

148 Starting in the Early Medieval Period (ca. $11^{\text {th }}$ century CE) human activity in Switzerland intensified (Egli, 149 1988). The foundation and construction of the first Medieval fortress in Murten by the Burgundians began in 150 the year $814 \mathrm{CE}$ (Schöpfer, 2016). The city of Murten remains the largest conurbation in the catchment today. 151 The Industrial Period was characterized by several water-corrections and drainage of the swamp area north of 152 the lake, paving the way for intensive agriculture (Nast, 2006).

154 In a previous study we showed that drastic increases in soil erosion indicators such as relative X-ray

155 fluorescence titanium (XRF Ti) concentrations, magnetic susceptibility (MS) and sediment mass accumulation 156 rates (MAR) were correlated with the timing of Roman land-use 2000 years ago and the Industrial Period 157 (Haas et al., 2019). The bulk sediment ${ }^{14} \mathrm{C}$ time series that was previously established (Haas et al., 2019) 158 offers an ideal base for our present study. Increasing age-offsets between bulk sedimentary organic carbon and 159 the modeled deposition age revealed terrestrial runoff of pre-aged SOC due to human induced soil erosion.

160 Interestingly, with the end of the Roman Period and relaxation of human pressure, soil erosion indicators 161 including the bulk sediment age offsets decreased and reached steady conditions around 200 years after 162 human activity ceased, which was interpreted as a period of renaturation and soil stabilization (Haas et al., 163 2019).

165 In the present study we worked on the same sedimentary record. Here, we add a new palynological data set 166 that allows us to expand our knowledge about the vegetation dynamics and history of agriculture in the 
catchment and to clearly identify land-use activity. Our present paleoecological overview compares well with former palynological work at Lake Murten (Hadorn, 1984). In addition, in the present study we focused on specific leaf waxes of terrestrial origin, which ensures better source control than the bulk SOC studied previously, and allows us to draw direct conclusions about the impact of land-use and abandonment on soil carbon dynamics.

\section{Material and Methods}

\subsection{Chronology}

The chronology of the Lake Murten sediment record (Latitude: 46.929220, Longitude: 7.067460, Haas et al., 2019 ) is based on 25 radiocarbon dates on terrestrial macrofossils, varve counting and ${ }^{137} \mathrm{Cs}$ radionuclide dating. Compared to the age-depth model of Haas et al. (2019), 15 additional radiocarbon ages on terrestrial plant macrofossil were obtained (Figure 2, appendix A). We followed the procedure of Haas et al. (2019) to prepare the additional macrofossil assemblages for radiocarbon dating on an EA-AMS (MICADAS, ETH Zürich). Furthermore, the sampling error was estimated using the sample thickness and the average sedimentation rate of approximately 8 years $/ \mathrm{cm}(\mathrm{y} / \mathrm{cm})$ and added to the analytical error of the radiocarbon dates using error propagation (see appendix A). Instead of classic (linear) age-depth modeling as used in Haas et al. (2019) (clam by Blaauw, 2010), we used a new approach using Bayesian statistics to reconstruct sediment accumulation rates for sediment records, implemented in the program BACON (Blaauw and Christen, 2011). BACON subdivides a sediment record into numerous vertical sections and estimates the sedimentation rate (in $\mathrm{y} / \mathrm{cm}$ ) using millions of Markov Chain Monte Carlo (MCMC) iterations. The model was calculated with a mean sedimentation rate (acc.mean) of $5 \mathrm{y} / \mathrm{cm}$ and an "accumulation shape" (acc.shape) of 1.5 on 101 sections of $10 \mathrm{~cm}$ thickness (Figure 2). Ages in this article are reported as Before Common Era (BCE) and Common Era (CE), respectively.

The application of this new age model resulted in larger confidence intervals, and some events described in our previous publication (Haas et al., 2019) became older by approximately a 100 years. All interpreted events and changes described in Haas et al. (2019), however, fall into the $95 \%$ confidence interval (CI) of the updated age-model and thus retain their significance. 
196 Figure 2: A. Age-depth model of the Lake Murten sediment record based on varve counting, radionuclide

$197{ }^{137} \mathrm{Cs}$ and radiocarbon dating on macrofossils. The lithological description follows Haas et al. (2019).

198 Abbreviations: Mesolithic Period (MP), Iron Age (IA), Bronze Age (BA), confidence interval (CI). B.

199 Enlarged zoom of the top $40 \mathrm{~cm}$ of the core. C. and D. prior (green) and posterior (grey) distributions of the 200 sedimentation rate and memory, respectively, that were used in the program BACON (appendix A) for age201 depth modelling (Blaauw and Christen, 2011).

\subsection{Pollen, spore and microscopic charcoal analysis}

204 The palynological results are presented in percentages of the terrestrial pollen sum (Fig. 3, appendix B).

205 Laboratory treatment followed standard preparation procedures for glycerin samples after Moore et al. (1991).

206 Lycopodium tablets were added to the samples prior to chemical and physical treatment in order to estimate 207 pollen and charcoal concentrations (grains or particles $/ \mathrm{cm}^{3}$ ) and charcoal influx (particles $/ \mathrm{cm}^{2} /$ year, 208 Stockmarr, 1971). Pollen, spores and microscopic charcoal particles from 40 samples $\left(1 \mathrm{~cm}^{3}\right)$ were analyzed. 209 In each of these, a pollen sum of $>500$ terrestrial pollen grains (except sample at $317.5 \mathrm{~cm}$ ) per sample were 210 counted. The pollen results are presented in percentages calculated on the terrestrial pollen sum. Pollen grains, 211 spores and other non-pollen palynomorphs (NPP) were identified using palynological keys and photo 212 references (Beug, 2004; Moore et al., 1991; Reille, 1995). Coprophilous fungal spores were identified 213 following van Geel et al. (2003). Microscopic charcoal particles were counted according to Finsinger and 214 Tinner (2005) and Tinner and $\mathrm{Hu}$ (2003). In total, 146 palynological taxa were identified in the sedimentary 215 record of Lake Murten. The results (counts) were normalized relative to the total pollen sum and displayed as 216 percentages. The pollen record was subdivided into three statistically significant local pollen assemblage 217 zones (PMUR-1-3) using constrained clustering, implemented in the program ZONE 1.2 (Juggins, 1991), and 218 the broken stick model (BSTICK) to determine the number of statistically significant zones (Bennett, 1996). A 219 diagram with a selection of the most important pollen, spore and non-pollen palynomorphs for the 220 paleoecological overview and the discussion of land-use activity can be found in the appendix B. 
223 Total lipid extracts (TLEs) were obtained from $\sim 10 \mathrm{~g}$ of freeze-dried, ground, and homogenized sediment from 224 each selected depth using a microwave extraction system (Milestone, MLS 1200 mega) with $10-15 \mathrm{ml}$ of $22510 \%$ methanol in dichloromethane (DCM) (2 min with $300 \mathrm{~W}$ from room temperature to $70^{\circ} \mathrm{C}$ and 5 min with $226500 \mathrm{~W}$ at $\left.70^{\circ} \mathrm{C}\right)$. The TLE was eluted over an aminopropyl column (1 g, Sigma Aldrich, LC-NH2 SPE Bulk) 227 with different solvents of increasing polarity. The first fraction (containing $n$-alkanes) was eluted with $10 \mathrm{ml}$ 228 of $n$-hexane, the second fraction with $4 \mathrm{ml}$ of $20 \%$ DCM in $n$-hexane, the third fraction with $4 \mathrm{ml}$ of $10 \%$ 229 acetone in DCM and the fourth fraction (containing $n$-carboxylic acids) with $2 \%$ formic acid in DCM.

231 The fractions containing $n$-carboxylic acids were derivatized to form fatty acid methyl esters (FAMEs) using $23210 \mathrm{ml}$ of $5 \%$ hydrochloric acid $(32 \%)$ in methanol and heated at $70^{\circ} \mathrm{C}$ for $12 \mathrm{~h}$. The organic phase was 233 recovered by liquid-liquid extraction with $n$-hexane. The resulting FAMEs were purified with a silver nitrate 234 coated silica gel pipette column (0.4 g, Sigma Aldrich) using different solvents of increasing polarity. The first 235 fraction was eluted with $2 \mathrm{ml}$ of $n$-hexane and the second fraction (containing the saturated $n$-carboxylic acid 236 FAMEs), with $4.5 \mathrm{ml}$ of $20 \%$ DCM in $n$-hexane.

238 The fractions containing $n$-alkanes were purified using a zeolite pipette column $(0.2 \mathrm{~g}$, Geokleen, 239 GHGeochemical Services) with $n$-hexane following the method of Haas et al. (2017). Aliquots of the purified $240 n$-alkane and $n$-carboxylic acid samples were analyzed by gas chromatography mass spectrometry (GC-MS, 241 5977B MSD, Agilent Technologies) and quantified for their concentrations, average chain lengths (ACL, after 242 Poynter and Eglinton (1990)) and carbon preference indices (CPI, after Bray and Evans (1961)) on the GC243 MS using the flame ionization detector (FID) attached to the same instrument. To minimize ${ }^{14} \mathrm{C}$ contamination 244 only external $n$-alkane $\left(n \mathrm{C}_{7-40}\right)$ and $n$-carboxylic acid standards $\left(n \mathrm{C}_{16+22+24+28}\right)$ were used for quantification. A 245 summary of the leaf wax data is added in the appendix C.

\subsection{Compound-specific radiocarbon dating}

248 Nine samples with highest concentrations of leaf waxes were selected for compound specific radiocarbon dating. Specific $n$-alkane homologues $n$ - $\mathrm{C}_{27}, n-\mathrm{C}_{29}, n-\mathrm{C}_{31}, n-\mathrm{C}_{33}$ and $n$ - $\mathrm{C}_{35}$ were collected using a GC-FID 
compound fractions were recovered from the PFC glass traps by elution with $1 \mathrm{ml} n$-hexane. Column bleed was removed by eluting the samples with $n$-hexane over a silica gel pipette column $(0.1 \mathrm{~g}$, Fluka Analytical).

253 The transfer of the compound fraction into an EA tin capsule (Säntis AG) was performed by repetitive 254 dissolution and transfer with DCM. A heat plate $\left(37^{\circ} \mathrm{C}\right)$ was used to evaporate the DCM. To obtain sufficient quantities for radiocarbon dating, several compound fractions needed to be pooled (13 samples for CSRA) and in some cases the bulk $n$-alkane fraction, containing every chain length, was used for radiocarbon dating (19 bulk $n$-alkane samples). A sample list including the radiocarbon results is given in appendix D.

Radiocarbon analyses of the $n$-alkane fractions were performed on an accelerated mass spectrometer (AMS) equipped with an elemental analyser (EA) at the Laboratory for Ion Beam Physics of ETH Zürich, Switzerland (MICADAS, Wacker et al., 2013). To monitor recoveries and ${ }^{14} \mathrm{C}$-backgrounds, specific $n$-alkane standards ( $n$ - $\mathrm{C}_{28}$ and $\left.n-\mathrm{C}_{32}\right)$ with known ${ }^{14} \mathrm{C}$-concentration (Fm of 0 and $\mathrm{Fm}$ of 1.073 , respectively) were processed. Samples that went through compound separation (GC-PFC) were corrected for the constant background contamination with GC-PFC processed $n-\mathrm{C}_{28}$ and $n-\mathrm{C}_{32}$. Bulk $n$-alkane fractions were corrected with unprocessed $n-\mathrm{C}_{28}$ and $n$ - $\mathrm{C}_{32}$. A constant contamination correction was applied according to Hanke et al.

266 (2017)(A summary of the compound-specific radiocarbon data is given in appendix E). Based on the blank assessment only data with errors $(\mathrm{Fm})<8 \%$ and sample masses larger than $10 \mu \mathrm{g}$ of carbon were taken into account for the discussion.

All radiocarbon ages were calibrated with IntCal 13 (Reimer et al., 2013). Specific ages in this article are calibrated and represent the $95 \%$ confidence interval and median age. The results were compared with the

272 macrofossil based age model and bulk sediment ages from Haas et al. (2019) and 15 additional measurements 273 following the same procedure (Figure 2, appendix F). The mean transit time (MTT) represents the difference 274 between the bulk sediment age (Median) and the $n$-alkane age (Median) to the age model (i.e. sedimentation age) and is reported in years. MTT errors were calculated using error propagation (appendix E). 
278 FAME and $n$-alkane $\delta^{13} \mathrm{C}$ values were determined by gas chromatography - isotope ratio mass spectrometry 279 (GC-IRMS) at Eawag's Center for Ecology, Evolution and Biogeochemistry in Kastanienbaum, Switzerland. 280 A GC-1310 (Thermo Scientific, Bremen, Germany) was interfaced to a Delta Advantage IRMS (Thermo 281 Scientific) with a ConFlow IV (Thermo Scientific). Samples were injected with a TriPlusRSH autosampler to 282 a split/splitless injector operated in splitless mode at $280^{\circ} \mathrm{C}$. The oven was equipped with an InertCap $2835 \mathrm{MS} / \mathrm{NP}$ column $(0.25 \mathrm{~mm} \times 30 \mathrm{~m} \times 0.25 \mu \mathrm{m})$ (GL Sciences, Japan) and was heated from 80 to $215^{\circ} \mathrm{C}$ at $15^{\circ} \mathrm{C}$ $284 \mathrm{~min}^{-1}$, then to $320^{\circ} \mathrm{C}$ at $5^{\circ} \mathrm{C} \mathrm{min}^{-1}$, and then held at $320^{\circ} \mathrm{C}$ for 10 minutes. Column effluent was combusted at $2851020^{\circ} \mathrm{C}$.

287 Raw isotope ratios were converted to the VPDB scale using Thermo Isodat 3.0 software and pulses of 288 reference gas at the beginning and end of each analysis. The sample $\delta^{13} \mathrm{C}$ values were further corrected using 289 the linear regression of measured and known values for a standard mix of $n$-alkanes $\left(n-C_{17,19,21,23,25,28,34) \text { of }}\right.$ 290 known isotopic composition (provided by Arndt Schimmelmann, Indiana University), which was run at varying concentrations at the beginning and end of each sequence, as well as after every 6-8 injections of samples. This standard was also used to monitor for instrumental drift and for any isotope effects associated with retention time or peak size. The average standard deviation for these standards during the analysis period was $0.6 \%(n=182)$, and their average offset from known values was $-0.1 \%$. An additional quality control standard of $n$ - $\mathrm{C}_{29}$-alkane was analyzed at least three times per sequence, and had a standard deviation of 0.18 $\%_{0}(n=15)$ during the analysis period. FAME $\delta^{13} \mathrm{C}$ values were corrected for the carbon added during methylation by isotopic mass balance, and reported errors represent propagated errors from the replicate measurements and from the uncertainty associated with the added carbon, which was determined by methylating and analyzing phthalic acid of known isotopic composition (provided by Arndt Schimmelmann, $300 \quad$ Indiana University).

\section{Interpretative Framework and Results}

\subsection{Palynological indications for vegetation dynamics and land-use in the catchment}

304 The relative abundances of the tree, shrub and herb pollen, microscopic charcoal influx (particles/cm $/ \mathrm{y}$ ), as well as cultural indicators such as Cerealia type and Plantago lanceolata (ribwort plantain) pollen, and spores 
from coprophilous fungi have proven to be robust indicators for evaluating land-use dynamics and vegetation change (see Tinner et al. (2003) for further information). We focused on these proxies to reconstruct the history of agriculture and divided the pollen record into three local pollen zones (PMUR-1-3) in order to assess statistically significant vegetation changes (Fig. 3, appendix B).

The sediment record reaches back to approximately 5800 BCE, which falls into the Late Mesolithic Period (start of PMUR-1). There is no archaeological evidence of human settlements in the Swiss Plateau region at that time (UNESCO Palafittes, 2015). During PMUR-1, a dominance of pollen of temperate trees and shrubs such as Ulmus, Quercus, Tilia, Acer, Fraxinus, Corylus and Hedera helix and monolete fern spores were present, suggesting that mixed oak forests (Quercetum mixtum) dominated the region around Lake Murten (ca. 70\% tree pollen during the Neolithic Period, Fig. 3). At the same time pollen of Abies and Fagus reached their empirical limit, suggesting that these trees expanded locally (Birks and Tinner, 2016). Fagus sylvatica (beech) and Abies alba (silver fir) are both shade-tolerant mesophilous late-successional trees species. The shift to mixed beech forests was found throughout the entire Swiss Plateau during the Neolithic Period. At Lake Murten, a representative site for the western part of the Swiss Plateau close to the Jura Mountains, Fagus sylvatica was co-dominant with Quercus (Ammann, 1989; Hadorn, 1992; Richoz and Haas, 1995).

During the Neolithic Period of the core, the charcoal influx increased to 6500 particles $/ \mathrm{cm}^{2} / \mathrm{y}(n=14)$, indicative of moderate fire activity in the region. Generally, the fire history is similar to the temporally high resolution charcoal results from nearby Lake Lobsigen (ca. $20 \mathrm{~km}$ away, Tinner et al., 2005). After ca. 4500 BCE, fire sensitive taxa such as Ulmus, Tilia, Fraxinus, Acer and Hedera helix decreased, while pollen of pioneer species such as Betula, Corylus avellana and Salix and heliophilous Juniperus shrubs increased. These results are consistent with the overall slash and burn agricultural practices of the Neolithic Period. Plantago lanceolata pollen and Sporormiella spores were scattered throughout this sedimentary interval, but at concentrations that are suggestive of low levels of human activity during the Neolithic Period (Fig. 3).

Towards the end of the Neolithic Period (2540 BCE; Figure 3), the first pollen occurrence of Cerealia type (t.) was detected, revealing a probable human activity and field cultivation in particular. Around $2200 \mathrm{BCE}$, the 
334 cultural period of the early Bronze Age started. However, no crucial vegetation change is visible in the 335 overview pollen diagram from this time (Figure 3). The only indication of further human influence is a slight 336 rise in charcoal influx coupled with an increase of pollen from more disruption-resistant Fagus and Urtica.

338 Starting towards the end of the Late Bronze Age period (ca. 1100 BCE, PMUR-2), crucial changes in the 339 vegetation around the lake were observed, roughly coincident with the onset of the Iron Age cultural period 340 (800 - 20 BCE). We observed a slow but significant decrease in tree pollen percentages, down to $30 \%$ (650 341 CE, Figure 3). In the course of this forest decline, Fagus and Abies pollen in particular decreased 342 substantially. Furthermore, a notable peak in the charcoal influx of 14,360 particles $/ \mathrm{cm}^{2} / \mathrm{y}$ occurred around 343430 BCE (Figure 3). This so called Iron Age-peak in charcoal influx has also been observed at other sites in 344 the Swiss Plateau and south of the Alps (Tinner et al., 2003). The timing of deforestation seems to correlate 345 not only with the elevated charcoal influx, but also with the beginning of a continuous curve in the cultural 346 indicator proxies, such as Cerealia t., Plantago lanceolata or Poaceae pollen (Figure 3). As Cerealia t. pollen 347 are dispersed locally and do not reach large distances (Soepboer et al., 2007; Tinner et al., 2003), these results 348 suggest cereal fields were in close proximity to Lake Murten. The agricultural intensification during the Late 349 Iron Age to Roman Period was accompanied by a substantial expansion of meadow and ruderal species such 350 as Artemisia, Cichorioideae, Ranunculus acris t. and Rumex acetosa t. A similar development has also been 351 observed in pollen records from other sites in the Swiss Plateau, such as Lake Lobsigen (Ammann, 1989). 352 During the Iron Age, dung-spores (Sporormiella, Fig. 3) rose continuously and remained elevated throughout 353 the Roman Period, where a temporal maximum of $1.4 \%$ at $350 \mathrm{CE}$ was identified. Cerealia t. pollen 354 percentages also increased steadily during the Roman Period (20 BCE to $5^{\text {th }}$ century CE, Fig. 3). Furthermore, 355 the Roman Period stands out clearly in the pollen record and is characterized by the introduction of new crops 356 such as Castanea sativa, Juglans regia and Secale cereale. The last local pollen zone PMUR-3 started ca. 380 CE and was characterized by further deforestation (until 650 CE, 30\% tree pollen), mostly at the expense of Abies and Fagus. Following the deforestation peak (650

360 CE), tree pollen percentages increased again to $40-50 \%$, mainly due to the increase of Quercus pollen percentages (Fig. 3). From the Medieval Period to the $19^{\text {th }}$ century, oak stands provided an important 
362 livelihood in Switzerland, consistent with our findings. Cereal cultivation (Cerealia t.; Secale cereale) was

363 also prevalent during this time. Herb pollen percentages of cultural meadow and ruderal taxa such as Plantago

364 lanceolata, Poaceae, Urtica, Artemisia, Trifolium pratense t., etc. were present at a continuously high level,

365 indicating ongoing land-use in the nearby catchment area until today. The afforestation trend was

366 accompanied by a simultaneous increase in the shrubs Juniperus and Salix but also slight increases in Calluna

367 and Ericaceae pollen. The heathland components commonly grow on open patches at rather nutrient-poor and 368 extensive meadows.

371 Figure 3: Palynological indications for past land-use around Lake Murten, Switzerland. A. Abundance of 372 Cerealia type (including Secale cereale) and Plantago lanceolata pollen as well as Sporormiella spores. B. 373 Charcoal influx. C. Normalized abundance of tree, shrub and herb pollen, as well as the subdivision into 374 significant local pollen zones 1-3. The thick lines in A and B represent trends derived from a locally weighted 375 scatterplot smoothing (LOESS, $\operatorname{span}=0.3, \mathrm{n}=80$ ). Abbreviations: Mesolithic Period (MP), Roman Period 376 (R), Modern Times (MT).

\subsection{Sedimentary leaf wax distributions}

379 The range and relative molecular abundances of sedimentary leaf waxes have been widely used to trace 380 environmental changes (Bush and McInerney, 2013). Leaf waxes are produced to coat the vascular leaf 381 surface, and serve as an outer protection against the environment (Eglinton and Hamilton, 1967). Their 382 molecular components, such as long-chained $n$-alkanes or $n$-carboxylic acids, have a refractory structure and 383 are well preserved in the environment over geological time scales (Eglinton and Eglinton, 2008).

384 A common ratio to describe leaf wax distribution patterns is the average chain-length (ACL) of $n$-alkanes or $385 n$-carboxylic acids (Bush and McInerney, 2013) (Formula in appendix C). For sediments it has been proposed that the ACL of $n$-alkanes is a broad indicator of shifts in the catchment's plant community. A predominance of relatively long-chained $n$-alkanes (or $n$-carboxylic acids) is typical for leaf waxes originating from higher terrestrial plants (Eglinton and Hamilton, 1967). In contrast, $n$-alkanes from more aquatic sources, such as 
389 microalgae or macrophytes, typically have relatively high abundances of middle and short-chained

390 homologues (Ficken et al., 2000; Sachse et al., 2004).

392 In the sedimentary record of Lake Murten, ACL values of $n$-alkanes varied between 27.8 and 28.9 with a 393 mean of $28.4\left(n=71\right.$, Figure 4). $n-\mathrm{C}_{29}$ alkane was the most abundant homologue. The predominance of 394 relatively long-chained $n$-alkanes in the record indicates contributions of terrestrial leaf waxes sourced from 395 higher plants. ACL trends from Lake Murten sediment (Figure 4) are correlated with arboreal pollen 396 abundances (Figure 3), supporting the assumption that the leaf waxes are predominantly of terrestrial plant 397 origin.

The carbon preference index (CPI) measures the abundance of odd-numbered relative to even-numbered $n$-alkane chain-lengths (Formula in appendix C). High CPI values $(>1)$ are characteristic for most modern plants (Bush and McInerney, 2013). Hence, in a sedimentary sequence CPI can provide an information on whether the $n$-alkanes are likely derived from a plant source, or whether they have been subject to significant microbial degradation or petrogenic inputs, both of which are associated with lower CPI values and greater relative contributions from even-numbered $n$-alkane homologues (Haas et al., 2017; Tao et al., 2015).

The $n$-alkane distributions from the sediments of Lake Murten had CPI values ranging from 4.3 to 9.4 with a mean of 7.2, demonstrating a strong dominance of odd-numbered $n$-alkanes (appendix C). We thus conclude that fossil leaf wax contribution from bedrock and microbial degradation seem to be minimal and that the leaf waxes are well preserved in the sediments.

The ACL and CPI values of sedimentary $n$-carboxylic acid distributions also support the conclusion that leaf

412 waxes in Lake Murten are predominantly sourced from terrestrial leaf waxes (summarized leaf wax data is 413 given in appendix C). However, $n$-carboxylic acid and $n$-alkane distributions are highly variable within 414 different plant groups, species and even the plant itself and can be influenced by various environmental 415 factors, such as temperature and relative humidity (Bush and McInerney, 2013). Furthermore, the original 416 (terrestrial) leaf wax signal can be diluted during transport, deposition or degradation by addition of 
417 compounds of other sources (Bush and McInerney, 2013). This problem of source control can be mitigated by

418 using a compound-specific approach, focusing only on compound fractions of relatively known terrestrial

419 origin.

\section{3. $\delta^{13} C$ isotopic composition of sedimentary leaf waxes}

422 The carbon isotopic composition of specific long-chained leaf waxes can be useful for inferring relative leaf wax sources (Diefendorf and Freimuth, 2017). Plant physiology, carbon fixation mechanisms (which differ for

$424 \mathrm{C}_{3}$ and $\mathrm{C}_{4}$ plants) and environmental factors such as relative humidity and temperature are responsible for 425 pronounced differences in the $\delta^{13} \mathrm{C}$ signature of plant $\mathrm{OM}$ (Farquhar et al., 1982). Analyzing $\delta^{13} \mathrm{C}$ values of 426 specific leaf wax compounds in sediment allows relative inputs from various OM sources to be discriminated 427 (Rieley et al., 1991).

In Lake Murten, the $\delta^{13} \mathrm{C}$ values of sedimentary long-chained leaf waxes $\left(\delta^{13} \mathrm{C}_{\mathrm{lw}}\right)$, including the $n$ - $\mathrm{C}_{28}, n-\mathrm{C}_{30}$, $n$ - $\mathrm{C}_{32}$ carboxylic acids and $n-\mathrm{C}_{29}$ and $n-\mathrm{C}_{31}$ alkanes, ranged from -32.9 to $-37.3 \%$ with a mean value of 34.6\% $(n=41)$ (Figure 4). They were depleted by approximately 4\%o relative to the bulk sedimentary isotopic 432 composition $\left(\delta^{13} \mathrm{C}_{\text {bulk }}\right)$ measured by Haas et al. (2019), which ranged from -28.2 to $-32.0 \%$ with a mean value of $-30.1 \%(n=62)$. The $\delta^{13} \mathrm{C}$ values of shorter homologues such as $n$ - $\mathrm{C}_{21}$ alkanes or $n$ - $\mathrm{C}_{20}$ carboxylic acids were in the same range as their longer chained counterparts (appendix D). The relatively depleted carbon isotopic composition is consistent with the $\delta^{13} \mathrm{C}$ signature of higher terrestrial plants following the $\mathrm{C}_{3}$ pathway for carbon fixation (Mays et al., 2017; Rieley et al., 1991). This assumption is supported by relatively high ACL and CPI values for both $n$-alkanes and $n$-carboxylic acids. Since the $\delta^{13} \mathrm{C}$ values of long-and short438 chained $n$-alkanes and $n$-carboxylic acids differed only slightly relative to each other, we assume a similar 439 terrestrial leaf wax source for all these compounds. The offset of approximately $4 \%$ between $\delta^{13} \mathrm{C}_{\text {bulk }}$ and $440 \quad \delta^{13} \mathrm{C}_{\mathrm{lw}}$ values is attributed to the biosynthetic depletion of leaf waxes relative to the carbon isotopic 441 composition of the bulk plant tissue (Collister et al., 1994). Differences between $\delta^{13} \mathrm{C}_{\text {bulk }}$ and $\delta^{13} \mathrm{C}_{\mathrm{lw}}$ values can 442 also occur if the sedimentary OM incorporates isotopically-enriched OM from autochthonous sources such as 443 algae (Rieley et al., 1991). This possibility is unlikely in Lake Murten given the elevated ACL values and the 444 relatively depleted $\delta^{13} \mathrm{C}$ values of the short-chained $n$-carboxylic acids. 
446 The evaluation of simultaneous changes among different compound-specific $\delta^{13} \mathrm{C}$ signatures is an additional 447 approach to interpret changes in the sedimentary leaf wax sources (Diefendorf et al., 2010; Yamamoto et al., 448 2010). The $\Delta \delta^{13} \mathrm{C}$ offset (\%o) represents the difference between specific long- and short-chained leaf wax $\delta^{13} \mathrm{C}$ 449 values (Figure 4). In Lake Murten, the $\Delta \delta^{13} \mathrm{C}$ offset between $n-\mathrm{C}_{32}$ and $n$ - $\mathrm{C}_{28}$ carboxylic acids $\left(\Delta \delta^{13} \mathrm{C}_{32-28}\right)$ 450 showed the largest variations and seemed to react more sensitively to leaf wax source changes, compared to $451 \Delta \delta^{13} \mathrm{C}_{32-30}$ and $\Delta \delta^{13} \mathrm{C}_{30-28}$ (Figure 4). During most parts of the Neolithic Period and the Bronze Age, $\Delta \delta^{13} \mathrm{C}_{32-28}$ 452 values were positive, with the longer homologue typically 2\%o enriched relative to the shorter one. Starting 453 with the Iron Age, however, $\Delta \delta^{13} \mathrm{C}_{32-28}$ decreased steadily and reached negative values during the Roman and 454 the Medieval Period, indicating that $n$ - $\mathrm{C}_{28}$ carboxylic acid became relatively ${ }^{13} \mathrm{C}$-enriched relative to $n$ - $\mathrm{C}_{32}$ 455 carboxylic acid. The overall decrease in $\Delta \delta^{13} \mathrm{C}$ from the Late Iron Age to the Medieval Period (Figure 4) is coeval with a decrease in the abundance of trees in the catchment (Figure 3).

One possible explanation is that during most parts of the Neolithic Period and the Bronze Age, a greater 459 proportion of the $n$ - $\mathrm{C}_{28}$ carboxylic acids were sourced from trees, which on average have leaf waxes with 460 lower $\delta^{13} \mathrm{C}$ values than do non-woody $\mathrm{C}_{3}$ plants (Diefendorf and Freimuth, 2017; Magill et al., 2013). With 461 ongoing deforestation, relatively more of the sedimentary $n-C_{28}$ carboxylic acid would have been sourced 462 from non-woody C3 plants, making it more enriched than before and thus lowering the $\Delta \delta^{13} \mathrm{C}_{32-28}$ during 463 phases of land-clearing. This interpretation is supported by the overall variability in ACL and the arboreal 464 pollen abundances.

Enhanced primary production in Lake Murten could also explain the negative shift in $\Delta \delta^{13} \mathrm{C}_{32-28}$ values that began in the Late Iron Age and continued into the second half of the Medieval Period. $n$-Carboxylic acids produced by algae are relatively enriched in $\delta^{13} \mathrm{C}$ compared to terrestrial sources, and $n$ - $\mathrm{C}_{28}$ carboxylic acids can be produced by microalgae (van Bree et al., 2018; Volkman et al., 1980). Increased primary productivity within the lake could therefore also lower $\Delta \delta^{13} \mathrm{C}_{32-28}$ values by increasing the $\delta^{13} \mathrm{C}$ values of $n$ - $\mathrm{C}_{28}$ carboxylic acids. However, clear evidence of enhanced primary production and eutrophic conditions that led to varve 
the updated age-model, Haas et al., 2019). We assume that increased contributions of $n-\mathrm{C}_{28}$ carboxylic acids from microalgae would only be relevant for these documented periods of hypoxia. Furthermore, if decreases in the $\Delta \delta^{13} \mathrm{C}_{32-28}$ offset were caused by enhanced algal productivity, we would expect them to correspond to a decrease in the $n$-carboxylic acid ACL, which was not the case.

\subsection{Relative ages of sedimentary leaf wax compounds}

In addition to the complications stemming from multiple sources for specific leaf wax compounds, their relative ages might also vary depending on the time needed for the cascade from synthesis to primary deposition in soils, to transport and finally to re-deposition in sediments (Douglas et al., 2014). Compoundspecific radiocarbon dating (CSRA) allows the mean transit time of leaf waxes $\left(\mathrm{MTT}_{\mathrm{lw}}\right)$ between plant synthesis and deposition in the sedimentary environment to be estimated (Douglas et al., 2018). Relative changes in $\mathrm{MTT}_{\mathrm{lw}}$ are closely associated with soil processes that can influence the recalcitrant "deep" SOC pool (Douglas et al., 2018; Feng et al., 2013; Smittenberg et al., 2006). It has been proposed that pre-aged leaf waxes, as part of the recalcitrant SOC pool, are introduced into the carbon cycle during phases of land-use, when the structure of top- and subsoil gets disturbed (Butman et al., 2015; Douglas et al., 2018; Lal, 2002). In a sedimentary archive, periods of human land-use may thus be recorded in terms of increasing age-offsets (i.e. $\mathrm{MTT}_{\mathrm{lw}}$ ) between individual long-chained leaf waxes and the corresponding deposition age (Douglas et al., 2014; Gierga et al., 2016). This has the advantage that the influence of a potential hard water effect can be limited substantially compared to analyses on the heterogenous bulk sedimentary OC due to better source control (Gierga et al., 2016). The predominance of relatively long-chained $n$-alkanes (or $n$-carboxylic acids) in the sediments of Lake Murten is characteristic for leaf waxes originating from higher terrestrial plants (increased ACL, Eglinton and Hamilton, 1967). The ACL even increased with ongoing land use during the Roman agricultural period, suggesting that the increased age-offsets are unlikely to be due to an increase of aquatic plant material which might have radiocarbon ages affected by hard water. Additional evidence that the leaf wax age-offsets are unlikely to be caused by aquatic plant inputs comes from the relatively depleted $\delta^{13} \mathrm{C}$ values of these compounds $\left(\delta^{13} \mathrm{C}\right.$ from -32.9 to $-37.3 \%$ ). These are consistent with a $\mathrm{C} 3$ terrestrial plant origin, as aquatic plants tend to be somewhat more enriched in ${ }^{13} \mathrm{C}$ (Fry and Sherr, 1984). In Lake Murten, we thus interpret increases in $\mathrm{MTT}_{\mathrm{lw}}$ as an indicator of enhanced input of soil-derived and pre-aged leaf waxes, 
corresponding to periods of increased soil erosion. Decreasing $\mathrm{MTT}_{\mathrm{lw}}$, on the contrary, is interpreted as a sign of soil stabilization.

Compound-specific ${ }^{14} \mathrm{C}$ dating of long-chained $n$-alkanes as well as bulk $n$-alkane fractions revealed that mean ages of leaf waxes in Lake Murten sediments are hundreds of years older than the estimated deposition age of the surrounding sediment. On average the $\mathrm{MTT}_{\mathrm{lw}}$ ranged from -600 to 4850 years with a mean of 450 years (Figure 4). Due to low sample masses and the applied contamination corrections (appendix E) the errors of the $n$-alkane ${ }^{14} \mathrm{C}$ ages were relatively large (approximately $700 \mathrm{y}, n=32$ ). Compound-specific $n$-alkane samples with masses below $20 \mu \mathrm{g}$ carbon had the highest errors. In three cases (50, 1110 and $1900 \mathrm{CE})$ we were able to date two different fractions from the same bulk $n$-alkane sample. In all cases the ages of the different chainlength fractions differed significantly by several hundred years. However, we assume that this effect was caused by the strong sample mass dependency of radiocarbon dating of small samples rather than a primary environmental signal (Hanke et al., 2017). Most of the reported ages that seem too young (e.g. all $n$-C $\mathrm{C}_{31+33+35}$ alkane fractions, Figure 4) were measured on samples with a relatively low carbon content (ca. $12 \mu \mathrm{g} \mathrm{C}, n=$ 3). The effect of mass dependency was also visible when comparing the ages and errors of compound-specific fractions (all $<20 \mu \mathrm{g} \mathrm{C})$ and bulk $n$-alkane fractions (all $>20 \mu \mathrm{g} \mathrm{C}$ ). Certain measurement artifacts could be countered by applying a locally weighted scatter-plot smoothing function (LOESS) including both compoundspecific and bulk fractions. This smoothing function includes the assumption of a similar leaf wax source for short and long-chained homologues in the sediments of Lake Murten, which is supported by compoundspecific $\delta^{13} \mathrm{C}$ measurements and the sedimentary leaf wax distributions (more details can be found in appendix C). Due to the relatively large errors in the CSRA data, not all changes in $\mathrm{MTT}_{\mathrm{lw}}$ are significant. For this reason we only describe broad trends in the $\mathrm{MTT}_{\mathrm{lw}}$ data and compare it to $\mathrm{MTT}_{\mathrm{OC}}$, which has much smaller errors.

Figure 4: A. Average chain length of $n$-alkanes $n$ - $\mathrm{C}_{23-33}$ (ACL) from sediments of Lake Murten, Switzerland. B. $\delta^{13} \mathrm{C}$ composition of leaf waxes. C. $\Delta \delta^{13} \mathrm{C}$ offset. D. Mean transit time of different $n$-alkane fractions 
$528\left(\mathrm{MTT}_{\mathrm{lw}}\right)$ and bulk sediment $\left(\mathrm{MTT}_{\mathrm{OC}}\right)$. The thick lines represent trends derived from LOESS $(\operatorname{span} \sim 0.3, \mathrm{n}=$ 529 80). Abbreviations: Mesolithic Period (MP), Roman Period (R), Modern Times (MT).

\section{Discussion: History of land use in the Lake Murten catchment}

532 The first signs of human activity in the catchment area of Lake Murten appeared during the Neolithic Period, when several pile dweller communities occupied the lake shore (UNESCO Palafittes, 2015). In the Alpine region, early pastoral activity and slash and burn practices to gain arable land during this time are indicated by elevated charcoal influx, as well as the first occurrences of Sporormiella spores and Plantago lanceolata pollen (Dietre et al., 2017; Schwörer et al., 2014; Tinner et al., 2003; Wehrli et al., 2007). Although there is evidence of human activity around Lake Murten during this interval, no significant changes were observed in the sedimentary leaf wax distribution (ACL) and the overall $\delta^{13} \mathrm{C}_{\mathrm{lw}}$ isotopic composition (Figure 4). The $\mathrm{MTT}_{\mathrm{lw}}$ trend, on the other hand, indicates increased input of pre-aged leaf waxes from 5200 to $3400 \mathrm{BCE}(n=$ 3). Also, MTT $_{O C}$ values suggest that input of pre-aged organic carbon increased during the same interval. Early human activity might be responsible for the excursions in $\mathrm{MTT}_{\mathrm{lw}}$ and $\mathrm{MTT}_{\mathrm{OC}}$ values. An alternative 542 explanation comes from the lithological succession of the core. The early interval with elevated $\mathrm{MTT}_{\mathrm{lw}}$ and 543 MTT $_{\mathrm{OC}}$ values is mostly part of Unit $5(5600-3700 \mathrm{BCE})$, which is composed of sediments with high detrital element concentrations (Haas et al., 2019). This suggests either a new source of sediments, which could be due to naturally occurring river diversions, or a climatically caused increase in soil erosion corresponding to wetter climate conditions as suggested by Magny (2004).

Unit $5(957-766 \mathrm{~cm})$ was deposited during a reported lake level high-stand for 26 lakes in Western

549 Switzerland and France that occurred in the period of 4400 - 3950 BCE (Magny, 2004). In the Swiss lowlands 550 phases of higher lake-level were triggered by enhanced annual precipitation and lower summer temperatures (Magny, 2004), leading to an outwash of detritus and probably soil material, including pre-aged leaf waxes. The age-depth model was updated substantially compared to the model in Haas et al. (2019). As a result, the progression of the age-depth model during the Neolithic Period is rather uncertain (Figure 2, Unit 5, 957 - 766 $\mathrm{cm})$ and the variable MTT values are strongly dependent on the age-depth model. The largest confidence intervals (95\%) for the age-depth model occurred during Unit 5 (ca. 500 years, Figure 2) due to two 
radiocarbon dates that lie slightly outside the curve (Figure 2). If the model would be changed so that it would pass through these points more clearly, the corresponding deposition ages would have been older and thus the $\mathrm{MTT}_{\mathrm{lw}}$ and MTT $\mathrm{OC}$ values during Unit 5 much smaller. As a consequence, the errors in this part of the core would have been unrealistically small, which is why this version of the model was omitted (See appendix A for the alternative age-depth model).

All data in the lower part of the core until ca. 3700 BCE should be interpreted with caution. There are indications that the last two data points in the age-depth model could also be classified as uncertain due to a biostratigraphic event, namely the rise of Abies alba and Fagus sylvatica around 6000 BCE, that was observed in other palynological publications near the study area (Tinner et al., 2018). In the sediments of Lake Murten the first rise of Abies alba (above 2\%) occurred slightly earlier approximately 5000 - 5500 BCE (see appendix B). This could imply that the deposition ages of the lowermost sediments could also be older by ca. $500-$ 1000 years, and that the age-model rather shows a minimum age (see also appendix A for an alternative agedepth model). However, the resolution of the palynological analysis would need to be increased substantially in order to verify this assumption. After $3700 \mathrm{BCE}$, the age-depth model is relatively stable until today (Figure 2) and more accurate statements about environmental changes in the catchment can be made.

Towards the transition into the Bronze Age, around 2500 BCE, increasing Sporormiella, Plantago lanceolata percentages and also the first occurrence of Cerealia t. pollen were documented (Figure 3), demonstrating that human activity including cattle raising and arable farming in close proximity to the lake shore were increasing. This result is also in close agreement with archaeological evidence. Numerous pile dwelling remains from the Neolithic Period were found in and around Lake Murten and dated using dendrochronology (Schibler and Jacomet, 2010). The interval of increased human activity (ca. 3000 - 2000 BCE) in the Lake Murten sedimentary record corresponds well with the reported ages of pile dwellings excavated in Faug, Vallamand and Muntelier (Figure 1, UNESCO Palafittes, 2015).

Despite new innovations in agricultural field cultivation (as indicated by Cerealia t. pollen), no significant changes in the leaf wax distributions and $\delta^{13} \mathrm{C}_{\mathrm{lw}}$ signature could be detected at this time (Figure 4). Only the $\mathrm{MTT}_{\text {lw }}$ gradually decreased, whereas no changes in the bulk sediment age offset were visible during this 
584 period. Based on the long-lasting decrease in $\mathrm{MTT}_{\mathrm{lw}}$ and the disagreement with land-use indicators, we 585 assume climatic controls were more important than anthropogenic controls on the leaf wax transit time during 586 this period. Magny (2004) also suggested that warmer and dryer climatic conditions prevailed during this 587 period (ca. $2500 \mathrm{BCE}$ ), favoring wheat production. Decreased precipitation might naturally lower the outwash 588 of SOC and pre-aged leaf waxes without changing their distributions or $\delta^{13} \mathrm{C}$ values.

590 During the Bronze Age, from 2200 - 800 BCE, land-use indicators remained low, even though nine 591 archaeological sites of pile dwellings are known from this time (Figure 1, UNESCO Palafittes, 2015). The 592 only signs of land-clearing were a minor increase in the charcoal influx and decrease in tree pollen 593 percentages in the Early Bronze Age (1500 BCE). This timing also roughly correlates with one elevated $594 \mathrm{MTT}_{\mathrm{lw}}$ value, suggesting a short period of soil erosion. However, a higher sample resolution would be needed to confirm that land-clearing and shorter periods of soil erosion existed during this interval.

During the Iron Age, 800 - 15 BCE, tree percentages started to decrease steadily and the charcoal influx rose 598 to a distinct peak, ca. $430 \mathrm{BCE}$, indicating severe land clearing (Figure 3). The interval of deforestation during 599 the La Tène cultural period (Late Iron Age) to the Early Roman Period was also accompanied by sharp 600 increases in Sporormiella, Plantago lanceolata and Cerealia t. percentages, indicating the beginning of largescale farming with cattle raising and field cultivation in the region (Figure 3). The earlier increase in Sporormiella spores might suggest that pastoralism was dominant during the Late Iron Age. This past landuse period corresponds nicely with the increases in sediment mass accumulation rate and detrital input 604 documented in our previous study (Haas et al., 2019).

Evidently, land-use and deforestation also had an influence on the leaf wax composition. With the onset of the Late Iron Age, ACL increased significantly to a temporal maximum of 28.8 at $140 \mathrm{BCE}$ (Figure 4). At the same time, $\Delta \delta^{13} \mathrm{C}$ offsets started to decrease steadily, suggesting a change in the leaf wax source towards open grasslands. $\mathrm{MTT}_{\mathrm{lw}}$ and $\mathrm{MTT}_{\mathrm{OC}}$ trends increased simultaneously during the Iron Age, consistent with the growing influence of agriculture on soil erosion. 
612 The deforestation trend continued with the onset of the Roman Period, reflecting the high demand for wood 613 and arable land that was needed for the newly founded Roman city Aventicum and its 20'000 inhabitants, at 614 the southern shore of Lake Murten (Castella et al., 2015) (Figure 1). Increased land-use indicators such as 615 Sporormiella, Plantago lanceolata and Cerealia t. point towards large-scale farming and the extension of 616 human pressure on the environment.

618 In the leaf wax record, the Roman Period was accompanied by relatively high but decreasing ACL (from 28.4 619 to $28.0,70 \mathrm{BCE}-280 \mathrm{CE}$ ) and a slight decrease towards more ${ }^{13} \mathrm{C}$-depleted values for the leaf waxes (Figure 620 4). The $\Delta \delta^{13} \mathrm{C}$ offset increased slightly despite the overall downward trend, due to a pulse of ${ }^{13} \mathrm{C}$-depleted $n$ $621 \mathrm{C}_{28}$ carboxylic acids. This effect might originate from the affiliation of leaf waxes with soil aggregates.

622 Mineral matrix protection of leaf waxes could have served as an effective protection from microbial degradation or re-synthesis, which leads to a relative enrichment in $\delta^{13} \mathrm{C}$ (Douglas et al., 2018; Matsumoto et al., 2007; Vonk et al., 2010). The elevated CPI of about 9 at 110 CE (appendix D) would support the assumption that less microbially influenced leaf wax material affiliated with soil aggregates was washed into the lake during this time.

Correlating with the onset of Late Iron Age to Early Roman land-use, soil erosion indicators drastically increased, consistent with our previous study (Haas et al., 2019). The mean transit time of bulk sedimentary OC (MTT $\mathrm{OC}$ of 1500 years) peaked at $170 \mathrm{BCE}$ with the updated age-model, revealing terrestrial runoff of pre-aged SOC due to human induced soil erosion. In the leaf wax record, a similar peak was detected in the transit time ( $\mathrm{MTT}_{\mathrm{lw}}$ of around 700 years from $70 \mathrm{BCE}$ to $150 \mathrm{CE}$ ), supporting the hypothesis of Early Roman soil degradation in the catchment (Figure 4). There was minimal time-lag of around 100 years between the $634 \mathrm{MTT}_{\mathrm{lw}}$ and $\mathrm{MTT}_{\mathrm{OC}}$ maxima. This might be a source effect of the two different organic fractions. Sedimentary OM has a very heterogeneous composition, containing OC of various allochthonous and autochthonous sources of different origin and ages (Gierga et al., 2016). Additionally, bulk sediment ${ }^{14} \mathrm{C}$ data is prone to so called "hardwater effects", depending on the bedrock composition of the catchment. Due to the dissolution of 638 limestone, algae and aquatic plants incorporate dissolved inorganic carbon (DIC) that is considered radiocarbon dead, which may lead to a dilution of the bulk sediment ${ }^{14} \mathrm{C}$-concentration (Fowler et al., 1986). 
640 The sedimentary leaf waxes, on the contrary, are predominantly of terrestrial instead of aquatic origin and 641 offer a better source control. We thus posit that the $\mathrm{MTT}_{\mathrm{lw}}$ maximum during the Early Roman Period was 642 mainly the result of anthropogenic soil erosion.

644 The input of pre-aged leaf waxes might have an effect on common ratios such as ACL, CPI and $\delta^{13} \mathrm{C}_{\mathrm{lw}}$ records 645 (Douglas et al., 2014). Due to the time lag between synthesis and sedimentary deposition, the environmental 646 signals might be delayed by the transit time of the individual compounds. In the Lake Murten setting, 647 however, this effect appears to be restricted to the periods of land-use. During times of land-use and enhanced 648 soil input we detected rising ACL, $\Delta \delta^{13} \mathrm{C}$ offsets and $\mathrm{MTT}_{\mathrm{lw}}$ but decreasing $\delta^{13} \mathrm{C}_{\mathrm{lw}}$ values (Figure 4). The 649 described excursions correspond well with the palynologically derived land-use periods and do not show 650 significant time lags, suggesting that only a smaller portion of the long-chained leaf waxes were pre-aged. 651 During undisturbed times, the sedimentary leaf wax distribution (ACL and $\Delta \delta^{13} \mathrm{C}$ offsets) seems to have been controlled by vegetation and the ecological changes inferred from the independent pollen record (Figure 3).

After the fall of the Roman Empire, during the Early Medieval Period, land-use indicators such as the charcoal influx as well as Sporormiella or Plantago lanceolata percentages decreased (ca. $650 \mathrm{CE}$ ). At this point the forest around Lake Murten had been decimated to ca. $20 \%$ of its initial extent. Historically, these sediments were deposited during the Great Migration Period (ca. $4^{\text {th }}$ to $6^{\text {th }}$ century CE), which is poorly represented in archaeological findings (Nast, 2006). Tinner et al. (2003) documented a reduction of agricultural activities around the 6th century CE accompanied by a short period of renaturation in three Swiss lakes. In the Lake Murten pollen record, afforestation was also identified, but several hundred years later, ca. 700 CE (Figure 3).

661 The timing discrepancy can either be assigned to the low sample resolution, an inaccurate age-depth relation, 662 and/or to regional differences in population discontinuities in Switzerland.

664 In the leaf wax record a minimum in the ACL trend occurred (ACL of ca. 28.2, 350 CE), which might be 665 indicative of a slight renaturation and forest regrowth during this period (Figure 4). This agrees with the $666 \mathrm{MTT}_{\mathrm{lw}}$ values, which steadily decreased and reached a temporal minimum of -340 years at $390 \mathrm{CE}$, suggesting 667 soil stabilization due to vegetation regrowth. A similar trend in the MTT OC was observed. Since Aventicum 
668 most likely had its largest population in the first two centuries CE, approximately $200-300$ years of soil 669 stabilization was needed to reach $\mathrm{MTT}_{\mathrm{lw}}$ values similar to those before the great land-clearing episode.

671 After $1000 \mathrm{CE}$, the tree pollen percentages decreased slightly, probably marking the growing influence of 672 Medieval agriculture in the region (Figure 3). Charcoal influxes, however, remained at a relatively low level 673 (around 7100 particles $/ \mathrm{cm}^{2} / \mathrm{y}$ ), which might indicate that less effort was needed to re-open the shrub674 dominated lands compared to the Late Iron Age to Early Roman Period. Palynological indicators, such as 675 Cerealia t. and Plantago lanceolata pollen and Sporormiella spores, were present in approximately the same 676 range as in the Roman Period, demonstrating active Medieval land-use in the catchment. The observed 677 changes also agree with historical developments. The Burgundians built the Early Medieval fortress of Murten 678 in $814 \mathrm{CE}$ on a pre-existing village back from Celtic to Roman times (documented as Muratum, $515 \mathrm{CE}$ ) 679 (Schöpfer, 2016). In the leaf wax record, Medieval land-use was only partly recorded. ACL rose to relatively high values ( $>28.5$, $6821000 \mathrm{CE}$ ) starting in the second half of the Medieval Period, probably indicating elevated input of leaf waxes 683 of terrestrial origin (Figure 4). Around the same time, MTT $_{\text {lw }}$ rose to 1900 years $(900 \mathrm{CE})$, reaching a 684 temporal maximum. In the MTT $\mathrm{OC}_{\mathrm{OC}}$ no temporal maximum was detected but rather a steady increase (Haas et al., 2019). This agrees with the results of our previous study, where we documented elevated detrital input during the Medieval Period (Haas et al., 2019). Building on previous argumentation we thus assume that an increase of human-induced soil erosion was responsible for this aging-effect in the sedimentary leaf-wax record.

Around $1830 \mathrm{CE}$, the charcoal influx increased again and tree pollen percentages reached another minimum, revealing a short period of deforestation during the course of the industrialization (Figure 3). Cultural indicators such as Plantago lanceolata, and new indicators, e.g. Platanus, Zea mays, and Carum carvi, increased significantly, suggesting high human activity in the catchment. This last development agrees with 694 the mechanization of agriculture, drainage of swamps and several water level corrections that accompanied 695 the intensification of agriculture in the region around the lake (Nast, 2006). 
697 The effect of land-use on the leaf wax composition is more pronounced during the Industrial Period compared 698 to the Roman or Medieval land-use periods (Figure 4). Simultaneous changes in the $\delta^{13} \mathrm{C}$ values of leaf wax 699 compounds, towards more depleted values, and the steep increase in $\mathrm{MTT}_{\mathrm{lw}}$ (Maximum of 4850 years, 1950

$700 \mathrm{CE}$ ) show that soil erosion increased substantially. New agricultural innovations, including mechanization, 701 allowed deeper plowing and most likely led to a more efficient mobilization of the deep SOC pool.

702 Furthermore, the large-scale water corrections that were applied during this time contributed to declining lake 703 surface levels and to the draining of the large swamp areas north of the lake to make new land for agriculture 704 available. Therefore, destabilization of the peatlands, leading to soil subsidence and erosion, might also be 705 responsible for the recent increase in $\mathrm{MTT}_{\mathrm{lw}}$.

\section{Conclusions}

708 A detailed reconstruction of the land-use history and its long-term impact on the environment in the Swiss 709 Plateau was produced through a combination of lake sediment pollen, spore, non-pollen palynomorphs and 710 microscopic charcoal analysis, as well as the evaluation of the distribution, carbon isotopic composition and 711 the relative ages of sedimentary leaf waxes in Lake Murten. Although pile dweller communities of the 712 Neolithic Period and the Bronze Age left their traces in the sedimentary record (low level slash and burn 713 agriculture, first cultural indicators for human activity), their influence on the local environment seems to have 714 been minimal. Based on a comparison of the relative input of soil-derived leaf waxes and independent lake 715 level reconstructions, we conclude that soil erosion during the Neolithic Period and the Bronze Age was 716 mostly driven by precipitation.

718 With the onset of the Late Iron Age and the rise of the La Tène culture, human activities had a greater impact 719 on soil erosion in Lake Murten's catchment. At the beginning of the Iron Age (ca. 800 BCE), continuous 720 deforestation was initiated, including severe slash and burn practices around 400 BCE (Figure 3). Cultural 721 indicators increased distinctly. Land-use activities had an impact on the local carbon dynamics, triggering soil erosion and the outwash of SOC (Figure 4). With ongoing deforestation during the following Roman Period, 723 the effect of human pressure on the environment grew further. 
725 Following the rise of the Roman city Aventicum south of the lake, large-scale agriculture with field cultivation 726 made its entrance (Figure 2). Continuous soil degradation altered the sedimentary leaf wax distribution and $727 \quad \delta^{13} \mathrm{C}$ values, indicating enhanced input of terrestrial OM (Figure 4). Moreover, leaf wax radiocarbon dating 728 revealed an increase in the mean transit time $\left(\mathrm{MTT}_{\mathrm{lw}}\right)$ of the soil-derived compounds, suggesting that soil 729 erosion was able to deplete the recalcitrant SOC pool. This supports the main findings from our previous 730 study where we documented that outwash of soil OM due to soil erosion during the Early Roman Period was responsible for eutrophication of the lake, resulting in deposition of varved sediments.

After the fall of the Roman Empire human pressures decreased and a period of renaturation occurred. During the Great Migration Period ( $4^{\text {th }}$ to $6^{\text {th }}$ century CE), land abandonment and a partial regrowth of the natural vegetation in the catchment helped stabilize the soils and remediated the SOC export back to pre-Roman values in approximately 200 years, as suggested by decreasing transit times of leaf waxes (Figure 4). A similar recovery rate was described in previous studies (Haas et al., 2019; Hillbrand et al., 2014). We assume that land-use was able to deplete the SOC pool, which might have resulted in long-lasting changes of the soil properties. For instance, we detected a significant shift in the plant community after the episode of Roman land-use, with mainly open, intensive to extensive cultivated area compared to the spacious woodlands (beech forests with silver fir and mixed oak elements) that existed during Neolithic times (Figure 3).

With the onset of Medieval agriculture (ca. $1000 \mathrm{CE}$ ) and the foundation of the city of Murten, a new wave of soil erosion and SOC outwash started. The following intensification of agriculture is visible not only in the pollen but also in the leaf wax record (Figure 3, 4). In particular, during the Industrial Period and the mechanization of agriculture a final but most prominent period of soil degradation was detected. During the modern land-use period, we assume soil erosion was also jointly responsible for recent eutrophication in Lake Murten that started around 1950. 
We would like to thank Serge Robert from Eawag, Silvia Bollhalder, Negar Haghipour and Lukas Wacker from the Laboratory of Ion Beam Physics at ETH Zürich and Marcel Bliedtner from the University of Jena for technical support during sample preparation, measurement and data interpretation. We would also like to thank Willy Tinner from the Institute of Plant Sciences at the University of Bern for facilitating the pollen analysis. Finally, we thank the Swiss National Science Foundation (SNSF) for funding the project “PALEOFARM”: Grant Nr. 200021_160066/1.

\section{Data Availability:}

Appendices A to F containing raw data tables are made available in the Mendeley data repository.

\section{References:}

Ammann, B., 1989. Late-Glacial palynology at Lobsigensee. Regional vegetation history and local Lake development. Diss. Bot. 137, 1-157.

Behre, K.-E., 1988. The role of man in European vegetation history, in: Huntley, B., Webb, T. (Eds.), Vegetation History. Springer Netherlands, Dordrecht, pp. 633-672. https://doi.org/10.1007/978-94-0093081-0_17

Bennett, K.D., 1996. Determination of the number of zones in a biostratigraphical sequence. New Phytol. 132, 155-170. https://doi.org/10.1111/j.1469-8137.1996.tb04521.x

Beug, H.J., 2004. Leitfaden der Pollenbestimmung für Mitteleuropa und angrenzende Gebiete. Publ. Verlag Friedrich Pfeil. https://doi.org/https://doi.org/10.1002/ardp.19622950723

Bichet, V., Gauthier, E., Massa, C., Perren, B., Richard, H., Petit, C., Mathieu, O., 2013. The history and impacts of farming activities in south Greenland: an insight from lake deposits. Polar Rec. (Gr. Brit). 49, 210-220. https://doi.org/https://doi.org/10.1017/S0032247412000587

Birks, H.J.B., Tinner, W., 2016. European tree dynamics and invasions during the Quaternary, in: Krumm, F., Vitkova, L. (Eds.), Introduced Tree Species in European Forests: Opportunities and Challenges. European Forest Institute, Freiburg, pp. 22-43. https://doi.org/citeulike-article-id:14216874

Blaauw, M., 2010. Methods and code for 'classical'age-modelling of radiocarbon sequences. Quat. Geochronol. 5, 512-518.

Blaauw, M., Christen, J.A., 2011. Flexible paleoclimate age-depth models using an autoregressive gamma process. Bayesian Anal. 6, 457-474. https://doi.org/10.1214/11-BA618

Bray, E.E., Evans, E.D., 1961. Distribution of n-paraffins as a clue to recognition of source beds. Geochim. Cosmochim. Acta 22, 2-15. https://doi.org/10.1016/0016-7037(61)90069-2

Bush, R.T., McInerney, F.A., 2013. Leaf wax n-alkane distributions in and across modern plants: Implications for paleoecology and chemotaxonomy. Geochim. Cosmochim. Acta 117, 161-179. https://doi.org/10.1016/J.GCA.2013.04.016

Butman, D.E., Wilson, H.F., Barnes, R.T., Xenopoulos, M.A., Raymond, P.A., 2015. Increased mobilization 
of aged carbon to rivers by human disturbance. Nat. Geosci. 8, 112-116. https://doi.org/10.1038/ngeo2322

Castella, D., Blank, P., Flück, M., Hufschmid, T., Krause, M.-F.M., 2015. Aventicum. Eine Römische Hauptstadt. Association Pro Aventico.

Collister, J.W., Rieley, G., Stern, B., Eglinton, G., Fry, B., 1994. Compound-specific $\delta 13 \mathrm{C}$ analyses of leaf lipids from plants with differing carbon dioxide metabolisms. Org. Geochem. 21, 619-627. https://doi.org/10.1016/0146-6380(94)90008-6

Cugny, C., Mazier, F., Galop, D., 2010. Modern and fossil non-pollen palynomorphs from the Basque mountains (western Pyrenees, France): the use of coprophilous fungi to reconstruct pastoral activity. Veg. Hist. Archaeobot. 19, 391-408. https://doi.org/10.1007/s00334-010-0242-6

Diefendorf, A.F., Freimuth, E.J., 2017. Extracting the most from terrestrial plant-derived n-alkyl lipids and their carbon isotopes from the sedimentary record: A review. Org. Geochem. 103, 1-21. https://doi.org/10.1016/J.ORGGEOCHEM.2016.10.016

Diefendorf, A.F., Mueller, K.E., Wing, S.L., Koch, P.L., Freeman, K.H., 2010. Global patterns in leaf 13C discrimination and implications for studies of past and future climate. Proc. Natl. Acad. Sci. U. S. A. 107, 5738-43. https://doi.org/10.1073/pnas.0910513107

Dietre, B., Walser, C., Kofler, W., Kothieringer, K., Hajdas, I., Lambers, K., Reitmaier, T., Haas, J.N., 2017. Neolithic to Bronze Age (4850-3450 cal. BP) fire management of the Alpine Lower Engadine landscape (Switzerland) to establish pastures and cereal fields. The Holocene 27, 181-196. https://doi.org/10.1177/0959683616658523

Douglas, P.M.J., Pagani, M., Eglinton, T.I., Brenner, M., Curtis, J.H., Breckenridge, A., Johnston, K., 2018. A long-term decrease in the persistence of soil carbon caused by ancient Maya land use. Nat. Geosci. 11, 645-649. https://doi.org/10.1038/s41561-018-0192-7

Douglas, P.M.J., Pagani, M., Eglinton, T.I., Brenner, M., Hodell, D.A., Curtis, J.H., Ma, K.F., Breckenridge, A., 2014. Pre-aged plant waxes in tropical lake sediments and their influence on the chronology of molecular paleoclimate proxy records. Geochim. Cosmochim. Acta 141, 346-364. https://doi.org/10.1016/j.gca.2014.06.030

Dubois, N., Jacob, J., 2016. Molecular biomarkers of Anthropic impacts in natural archives: A review. Front. Ecol. Evol. 4. https://doi.org/https://doi.org/10.3389/fevo.2016.00092

Edwards, K.J., Whittington, G., 2001. Lake sediments, erosion and landscape change during the Holocene in Britain and Ireland. Catena 42, 143-173. https://doi.org/10.1016/S0341-8162(00)00136-3

Egli, H.-R., 1988. Some Thoughts on the Origin of the Open Field System in Switzerland and Its Development in the Middle Ages. Geogr. Ann. Ser. B, Hum. Geogr. 70, 95-104. https://doi.org/10.1080/04353684.1988.11879554

Eglinton, G., Hamilton, R.J., 1967. Leaf epicuticular waxes. Science (80-. ). 156, 1322-1335. https://doi.org/10.1126/science.156.3780.1322

Eglinton, T.I., Eglinton, G., 2008. Molecular proxies for paleoclimatology. Earth Planet. Sci. Lett. 275, 1-16.

Enters, D., Lücke, A., Zolitschka, B., 2006. Effects of land-use change on deposition and composition of organic matter in Frickenhauser See, northern Bavaria, Germany. Sci. Total Environ. 369, 178-187.

Farquhar, G., O’Leary, M., Berry, J., 1982. On the Relationship Between Carbon Isotope Discrimination and the Intercellular Carbon Dioxide Concentration in Leaves. Aust. J. Plant Physiol. 13, 281-292. https://doi.org/10.1071/PP9820121 
Feng, X., Vonk, J.E., van Dongen, B.E., Gustafsson, O., Semiletov, I.P., Dudarev, O. V., Wang, Z., Montlucon, D.B., Wacker, L., Eglinton, T.I., 2013. Differential mobilization of terrestrial carbon pools in Eurasian Arctic river basins. Proc. Natl. Acad. Sci. 110, 14168-14173. https://doi.org/10.1073/pnas.1307031110

Ficken, K.., Li, B., Swain, D.., Eglinton, G., 2000. An n-alkane proxy for the sedimentary input of submerged/floating freshwater aquatic macrophytes. Org. Geochem. 31, 745-749. https://doi.org/10.1016/S0146-6380(00)00081-4

Finsinger, W., Tinner, W., 2005. Minimum count sums for charcoal-concentration estimates in pollen slides: Accuracy and potential errors. Holocene 15, 293-297. https://doi.org/10.1191/0959683605hl808rr

Foster, D., Swanson, F., Aber, J., Burke, I., Brokaw, N., Tilman, D., Knapp, A., 2003. The Importance of Land-Use Legacies to Ecology and Conservation. Bioscience 53, 77-88. https://doi.org/10.1641/00063568(2003)053[0077:tiolul]2.0.co;2

Fowler, A.J., Gillespie, R., Hedges, R.E.M., 1986. Radiocarbon Dating of Sediments. Radiocarbon 28, 441450. https://doi.org/10.1017/S0033822200007578

Fry, B., Sherr, E.B., 1984. $\delta 13 \mathrm{C}$ measurements as indicators of carbon flow in marine and fresh-water ecosystems. Contrib. Mar. Sci. 27, 13-47.

Galy, V., Eglinton, T., France-Lanord, C., Sylva, S., 2011. The provenance of vegetation and environmental signatures encoded in vascular plant biomarkers carried by the Ganges-Brahmaputra rivers. Earth Planet. Sci. Lett. 304, 1-12. https://doi.org/10.1016/J.EPSL.2011.02.003

Gierga, M., Hajdas, I., van Raden, U.J., Gilli, A., Wacker, L., Sturm, M., Bernasconi, S.M., Smittenberg, R.H., 2016. Long-stored soil carbon released by prehistoric land use: Evidence from compound-specific radiocarbon analysis on Soppensee lake sediments. Quat. Sci. Rev. 144, 123-131. https://doi.org/10.1016/J.QUASCIREV.2016.05.011

Haas, M., Baumann, F., Castella, D., Haghipour, N., Reusch, A., Strasser, M., Eglinton, T.I., Dubois, N., 2019. Roman-driven cultural eutrophication of Lake Murten, Switzerland. Earth Planet. Sci. Lett. 505, 110-117. https://doi.org/10.1016/J.EPSL.2018.10.027

Haas, M., Bliedtner, M., Borodynkin, I., Salazar, G., Szidat, S., Eglinton, T.I., Zech, R., 2017. Radiocarbon dating of leaf waxes in the Loess-Paleosol sequence Kurtak, central Siberia. Radiocarbon 59, 165-176. https://doi.org/10.1017/RDC.2017.1

Hadorn, P., 1992. Vegetationsgeschichtliche Studie am Nordufer des Lac de Neuchâtel: Pollenanalytische Untersuchungen im Loclat, in der Bucht von Hauterive/Saint-Blaise und in den neolithischen Ufersiedlungen von Saint-Blaise/Bain des Dames. Diss. Univ. Bern.

Hadorn, P., 1984. Pollenanalytische Untersuchungen über die jüngere nacheiszeitliche Vegetations- und Siedlungsgeschichte am Murtensee. Lizentiatsarbeit am Syst.-Geobot. Inst. der Univ. Bern.

Hanke, U.M., Wacker, L., Haghipour, N., Schmidt, M.W.I., Eglinton, T.I., McIntyre, C.P., 2017. Comprehensive radiocarbon analysis of benzene polycarboxylic acids (BPCAs) derived from pyrogenic carbon in environmental samples. Radiocarbon 59, 1103-1116. https://doi.org/10.1017/RDC.2017.44

Hillbrand, M., van Geel, B., Hasenfratz, A., Hadorn, P., Haas, J.N., 2014. Non-pollen palynomorphs show human- and livestock-induced eutrophication of Lake Nussbaumersee (Thurgau, Switzerland) since Neolithic times (3840 bc). Holocene 24, 559-568. https://doi.org/10.1177/0959683614522307

Huang, C.C., O'Connell, M., 2000. Recent land-use and soil-erosion history within a small catchment in Connemara, western Ireland: evidence from lake sediments and documentary sources. CATENA 41, 293-335. https://doi.org/10.1016/S0341-8162(00)00095-3 
Juggins, S., 1991. ZONE software. Newcastle Universtiy Newcastle upon Tyne.

Lal, R., 2005. Soil erosion and carbon dynamics. Soil Tillage Res. 81, 137-142. https://doi.org/10.1016/J.STILL.2004.09.002

Lal, R., 2004. Soil carbon sequestration impacts on global climate change and food security. Science (80-. ). $304,1623-1627$.

Lal, R., 2002. Soil carbon dynamics in cropland and rangeland. Environ. Pollut. 116, 353-362. https://doi.org/10.1016/S0269-7491(01)00211-1

Magill, C.R., Ashley, G.M., Freeman, K.H., 2013. Ecosystem variability and early human habitats in eastern Africa. Proc. Natl. Acad. Sci. U. S. A. 110, 1167-74. https://doi.org/10.1073/pnas.1206276110

Magny, M., 2004. Holocene climate variability as reflected by mid-European lake-level fluctuations and its probable impact on prehistoric human settlements. Quat. Int. 113, 65-79. https://doi.org/10.1016/S10406182(03)00080-6

Matsumoto, K., Kawamura, K., Uchida, M., Shibata, Y., 2007. Radiocarbon content and stable carbon isotopic ratios of individual fatty acids in subsurface soil: Implication for selective microbial degradation and modification of soil organic matter. Geochem. J. 41, 483-492. https://doi.org/10.2343/geochemj.41.483

Mays, J.L., Brenner, M., Curtis, J.H., Curtis, K.V., Hodell, D.A., Correa-Metrio, A., Escobar, J., Dutton, A.L., Zimmerman, A.R., Guilderson, T.P., 2017. Stable carbon isotopes ( $\delta 13 C)$ of total organic carbon and long-chain n-alkanes as proxies for climate and environmental change in a sediment core from Lake Petén-Itzá, Guatemala. J. Paleolimnol. 57, 307-319. https://doi.org/10.1007/s10933-017-9949-z

Menotti, F., 2004. Living on the lake in prehistoric Europe: 150 years of lake-dwelling research. Routledge.

Meyers, P.A., 1994. Preservation of elemental and isotopic source identification of sedimentary organic matter. Chem. Geol. 114, 289-302. https://doi.org/10.1016/0009-2541(94)90059-0

Moore, P.D., Webb, J.A., Collison, M.E., 1991. Pollen analysis, 2nd ed. Blackwell Scientific Publications, Oxford.

Nast, M., 2006. Überflutet - überlebt - überlistet: die Geschichte der Juragewässerkorrektionen. Verein Schlossmuseum Nidau.

Pfiffner, O.A., 2014. Geology of the Alps. John Wiley \& Sons.

Poynter, J.G., Eglinton, G., 1990. Molecular composition of three sediments from hole 717c: The Bengal fan. Proc. Ocean Drill. Program, Sci. Results 116, 155-161.

Quinton, J.N., Govers, G., Van Oost, K., Bardgett, R.D., 2010. The impact of agricultural soil erosion on biogeochemical cycling. Nat. Geosci. 3, 311-314. https://doi.org/10.1038/ngeo838

Reille, M., 1995. Pollen et spores d'Europe et d'Afrique du Nord: supplement 1. Marseille Lab. Bot. Hist. Palynol. 274p.-illus.

Reimer, P.J., Bard, E., Bayliss, A., Beck, J.W., Blackwell, P.G., Ramsey, C.B., Buck, C.E., Cheng, H., Edwards, R.L., Friedrich, M., 2013. IntCal13 and Marine13 radiocarbon age calibration curves 0-50,000 years cal BP. Radiocarbon 55, 1869-1887.

Richoz, I., Haas, J.N., 1995. Flora und Vegetation im Neolithikum der Schweiz - Flore et végétation au Néolithique en Suisse, in: Stöckli, W.E., Niffeler, U., Gross-Klee, E. (Eds.), Die Schweiz Vom Paläolithikum Bis Zum Frühen Mittelalter: Bd. II: Neolithikum. Verlag Schweizerische Gesellschaft für Ur- und Frühgeschichte, Basel, pp. 59-72. 
Rieley, G., Collier, R.J., Jones, D.M., Eglinton, G., Eakin, P.A., Fallick, A.E., 1991. Sources of sedimentary lipids deduced from stable carbon-isotope analyses of individual compounds. Nature 352, 425-427. https://doi.org/10.1038/352425a0

Sachse, D., Radke, J., Gleixner, G., 2004. Hydrogen isotope ratios of recent lacustrine sedimentary n-alkanes record modern climate variability. Geochim. Cosmochim. Acta 68, 4877-4889. https://doi.org/10.1016/J.GCA.2004.06.004

Schibler, J., Jacomet, S., 2010. Short climatic fluctuations and their impact on human economies and societies: the potential of the Neolithic lake shore settlements in the Alpine foreland. Environ. Archaeol. $15,173-182$.

Schöpfer, H., 2016. Murten (Gemeinde) [WWW Document]. Hist. Lex. der Schweiz. URL http://www.hlsdhs-dss.ch/textes/d/D1014.php (accessed 9.18.18).

Schwörer, C., Kaltenrieder, P., Glur, L., Berlinger, M., Elbert, J., Frei, S., Gilli, A., Hafner, A., Anselmetti, F.S., Grosjean, M., Tinner, W., 2014. Holocene climate, fire and vegetation dynamics at the treeline in the Northwestern Swiss Alps. Veg. Hist. Archaeobot. 23, 479-496. https://doi.org/10.1007/s00334-013$0411-5$

Smittenberg, R.H., Eglinton, T.I., Schouten, S., Sinninghe Damsté, J.S., 2006. Ongoing buildup of refractory organic carbon in boreal soils during the Holocene. Science (80-. ). 314, 1283-1286. https://doi.org/10.1126/science.1129376

Soepboer, W., Sugita, S., Lotter, A.F., van Leeuwen, J.F.N., van der Knaap, W.O., 2007. Pollen productivity estimates for quantitative reconstruction of vegetation cover on the Swiss Plateau. The Holocene 17, 6577. https://doi.org/10.1177/0959683607073279

Stockmarr, J.A., 1971. Tabletes with spores used in absolute pollen analysis. Pollen et Spores 615-621, 615621.

Tao, S., Eglinton, T.I., Montluçon, D.B., McIntyre, C., Zhao, M., 2015. Pre-aged soil organic carbon as a major component of the Yellow River suspended load: Regional significance and global relevance. Earth Planet. Sci. Lett. 414, 77-86. https://doi.org/10.1016/J.EPSL.2015.01.004

Tinner, W., Conedera, M., Ammann, B., Lotter, A.F., 2005. Fire ecology north and south of the Alps since the last ice age. The Holocene 15, 1214-1226. https://doi.org/10.1191/0959683605hl892rp

Tinner, W., Hu, F.S., 2003. Size parameters, size-class distribution and area-number relationship of microscopic charcoal: relevance for fire reconstruction. The Holocene 13, 499-505. https://doi.org/10.1191/0959683603hl615rp

Tinner, W., Lotter, A.F., Ammann, B., Conedera, M., Hubschmid, P., van Leeuwen, J.F.N., Wehrli, M., 2003. Climatic change and contemporaneous land-use phases north and south of the Alps $2300 \mathrm{BC}$ to $800 \mathrm{AD}$. Quat. Sci. Rev. 22, 1447-1460. https://doi.org/10.1016/S0277-3791(03)00083-0

Tinner, W., van der Knaap, W.O., Conedera, M., Ammann, B., 2018. Invasionen und Zusammenbrüche von Baumarten nach der Eiszeit. Schweizerische Zeitschrift fur Forstwes. https://doi.org/10.3188/szf.2018.0060

UNESCO Palafittes, 2015. UNESCO World Heritage - Prehistoric Pile Dwellings around the Alps [WWW Document]. Int. Coord. Gr. UNESCO Palafittes. URL http://sites.palafittes.at/ (accessed 9.20.18).

van Bree, L.G.J., Peterse, F., van der Meer, M.T.J., Middelburg, J.J., Negash, A.M.D., De Crop, W., Cocquyt, C., Wieringa, J.J., Verschuren, D., Sinninghe Damsté, J.S., 2018. Seasonal variability in the abundance and stable carbon-isotopic composition of lipid biomarkers in suspended particulate matter from a stratified equatorial lake (Lake Chala, Kenya/Tanzania): Implications for the sedimentary record. Quat. Sci. Rev. 192, 208-224. https://doi.org/10.1016/J.QUASCIREV.2018.05.023 
van Geel, B., Buurman, J., Brinkkemper, O., Schelvis, J., Aptroot, A., van Reenen, G., Hakbijl, T., 2003. Environmental reconstruction of a Roman period settlement site in Uitgeest (the Netherlands), with special reference to coprophilous fungi. J. Archaeol. Sci. 30, 873-883. https://doi.org/10.1016/S03054403(02)00265-0

Van Oost, K., Quine, T.A., Govers, G., De Gryze, S., Six, J., Harden, J.W., Ritchie, J.C., McCarty, G.W., Heckrath, G., Kosmas, C., Giraldez, J. V, da Silva, J.R.M., Merckx, R., 2007. The impact of agricultural soil erosion on the global carbon cycle. Science (80-. ). 318, 626-629. https://doi.org/10.1126/science.1145724

Volkman, J.K., Johns, R.B., Gillan, F.T., Perry, G.J., Bavor, H.J., 1980. Microbial lipids of an intertidal sediment-I. Fatty acids and hydrocarbons. Geochim. Cosmochim. Acta 44, 1133-1143. https://doi.org/10.1016/0016-7037(80)90067-8

Vonk, J.E., van Dongen, B.E., Gustafsson, Ö., 2010. Selective preservation of old organic carbon fluvially released from sub-Arctic soils. Geophys. Res. Lett. 37. https://doi.org/10.1029/2010GL042909

Wacker, L., Fahrni, S.M., Hajdas, I., Molnar, M., Synal, H.A., Szidat, S., Zhang, Y.L., 2013. A versatile gas interface for routine radiocarbon analysis with a gas ion source, in: Zondervan, A., Prior, C., Bruhn, F., Sparks, R. (Eds.), Nuclear Instruments and Methods in Physics Research Section B: Beam Interactions with Materials and Atoms. pp. 315-319. https://doi.org/10.1016/j.nimb.2012.02.009

Wehrli, M., Tinner, W., Ammann, B., 2007. 16000 years of vegetation and settlement history from Egelsee (Menzingen, central Switzerland). The Holocene 17, 747-761. https://doi.org/10.1177/0959683607080515

Yamamoto, S., Kawamura, K., Seki, O., Meyers, P.A., Zheng, Y., Zhou, W., 2010. Environmental influences over the last $16 \mathrm{ka}$ on compound-specific $\delta 13 \mathrm{C}$ variations of leaf wax n-alkanes in the Hani peat deposit from northeast China. Chem. Geol. 277, 261-268. https://doi.org/10.1016/J.CHEMGEO.2010.08.009 
Age-depth model B

(ky cal BP)

${ }^{137} \mathrm{Cs}(\mathrm{Bq} / \mathrm{kg})$

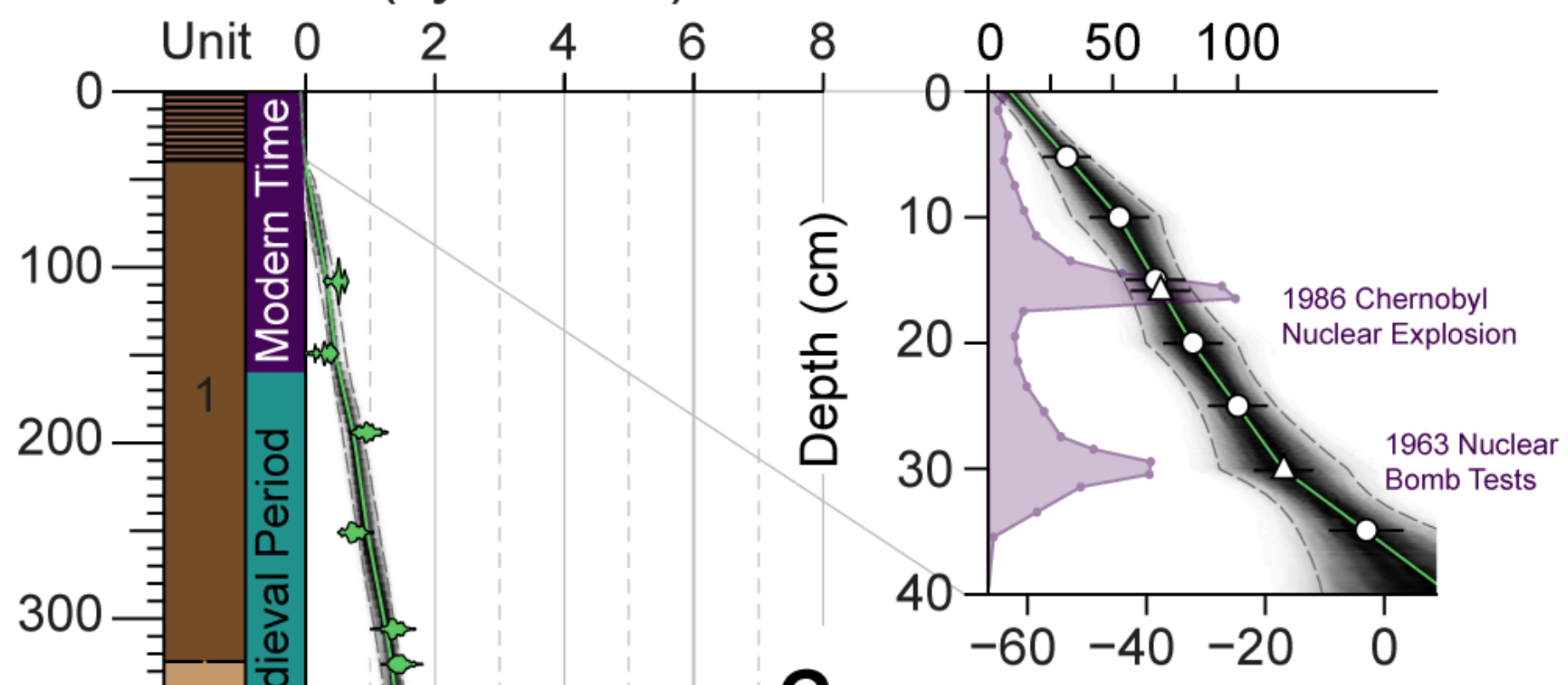

C
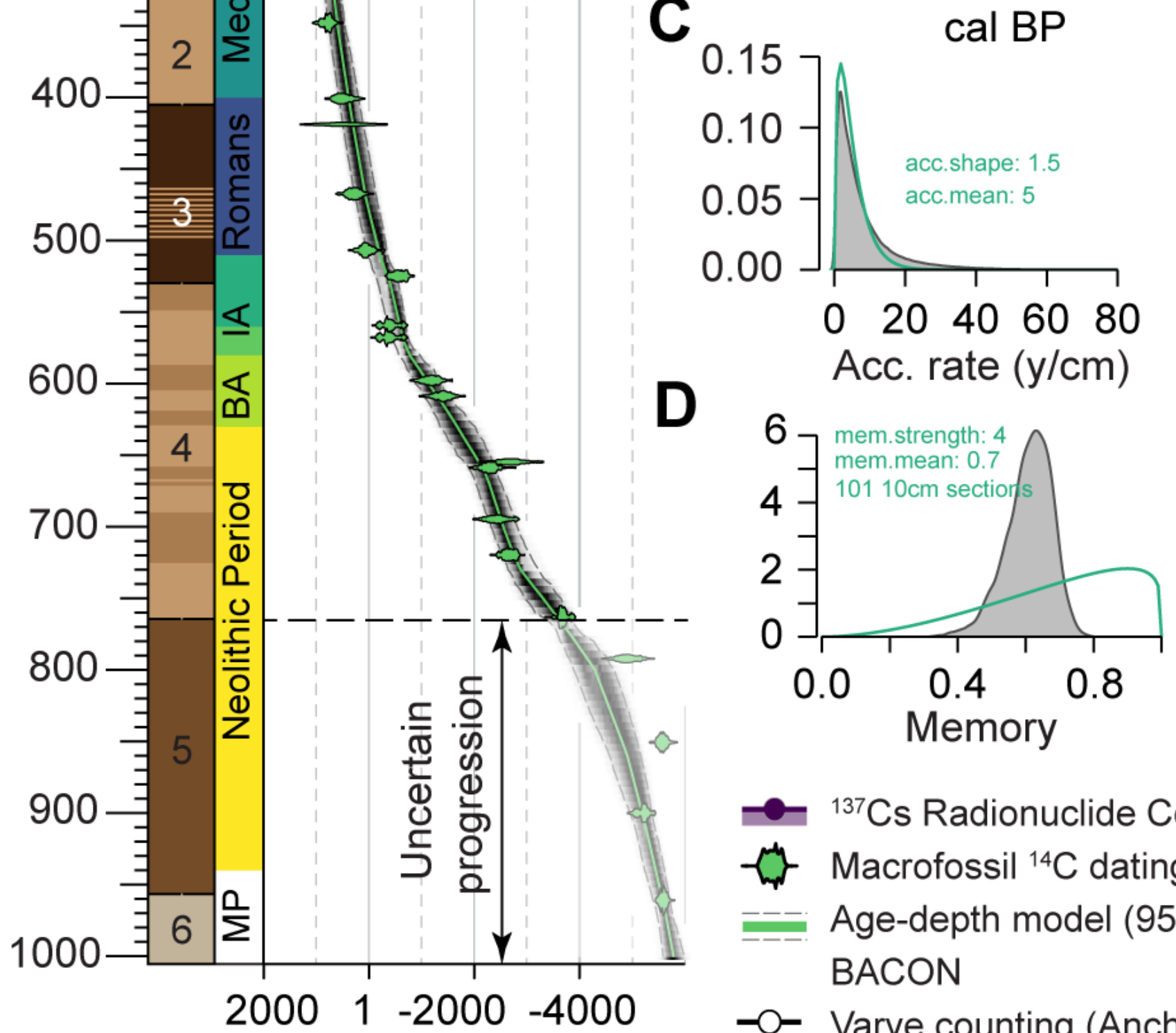

CE/BCE

- ${ }^{137}$ Cs Radionuclide Concentr.

- Try Macrofossil ${ }^{14} \mathrm{C}$ dating $(95 \% \mathrm{Cl})$

-_. Age-depth model $(95 \% \mathrm{Cl})$ BACON

$-\mathrm{O}-$ Varve counting (Anchor points)

$\triangle \quad{ }^{137} \mathrm{Cs}$ (Anchor points)

$\square$ Carbonate rich, homogeneous mud Homogeneous dark, slightly laminated

$\square \quad$ Carbonate rich sediments

$\equiv$ Varves

Organic rich sediments 


\section{Sediment Depth $(\mathrm{cm})$}

$\begin{array}{lllll}1000900 \quad 800 & 700 & 600 \quad 5004003002001000\end{array}$

@ $\quad 2$ - Cerealia type Pollen

4- Plantago lanceolata Pollen

B

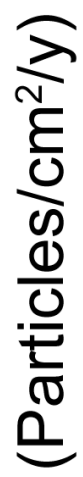

15000

Charcoal Influx

\section{Early Agriculture Pastures, Wheat}

0

2000

5000 -

10000 -

0

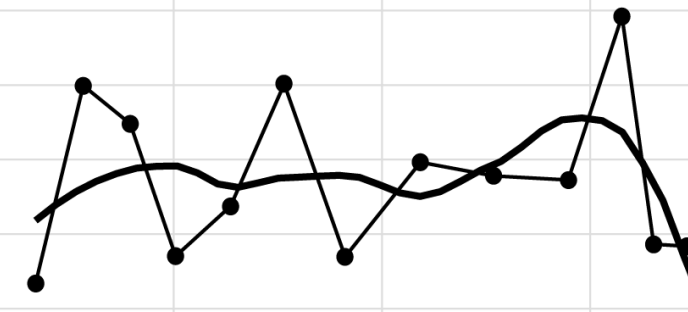

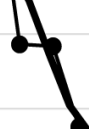

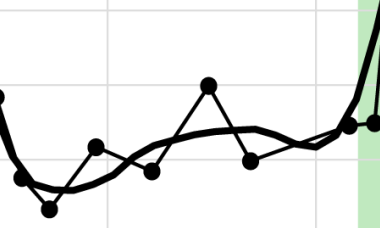

Deforestation

0

PMUR-2: PMUR-3

PMUR-1

2000

$100-$

बे

75 -

50 -

$\square$ Herbs

$\square$ Shrubs

$\square$ Trees

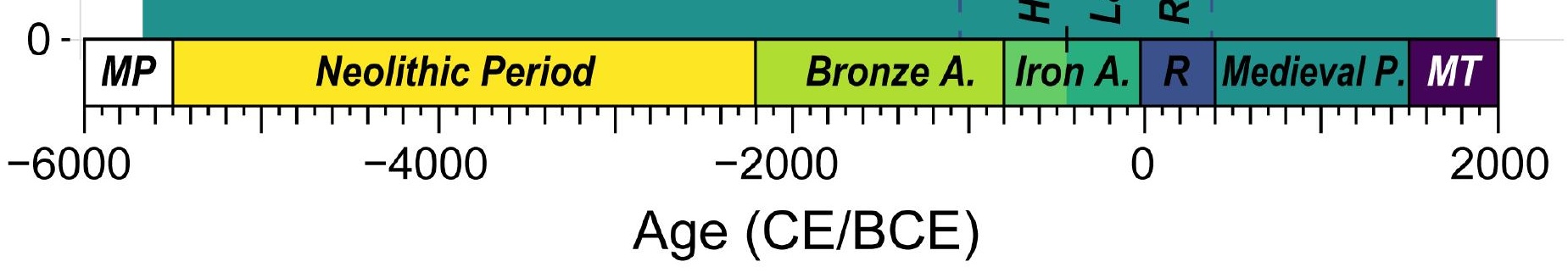


Sediment Depth (cm)

A $1000 \quad 900 \quad 800$ 700 6005004003002001000

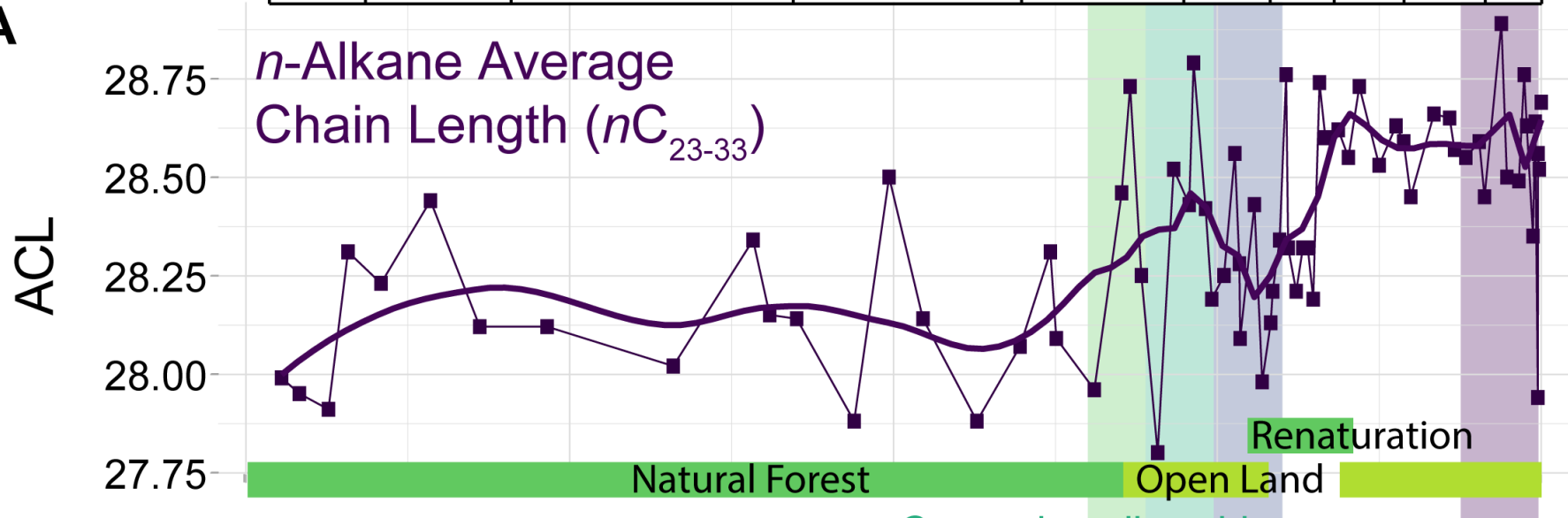

B

$\delta^{13} \mathrm{C}$ of Leaf Waxes

- $n \mathrm{C}_{28}$-carboxylic acid $\Delta n \mathrm{C}_{29}$-alkane - $n \mathrm{C}_{30}$-carboxylic acid $+n \mathrm{C}_{31}$-alkane $\otimes n \mathrm{C}_{32}$-carboxylic acid

$\begin{array}{ll}\underbrace{3}_{0} & -34 \\ \frac{0}{3} & -36\end{array}$

$-38$

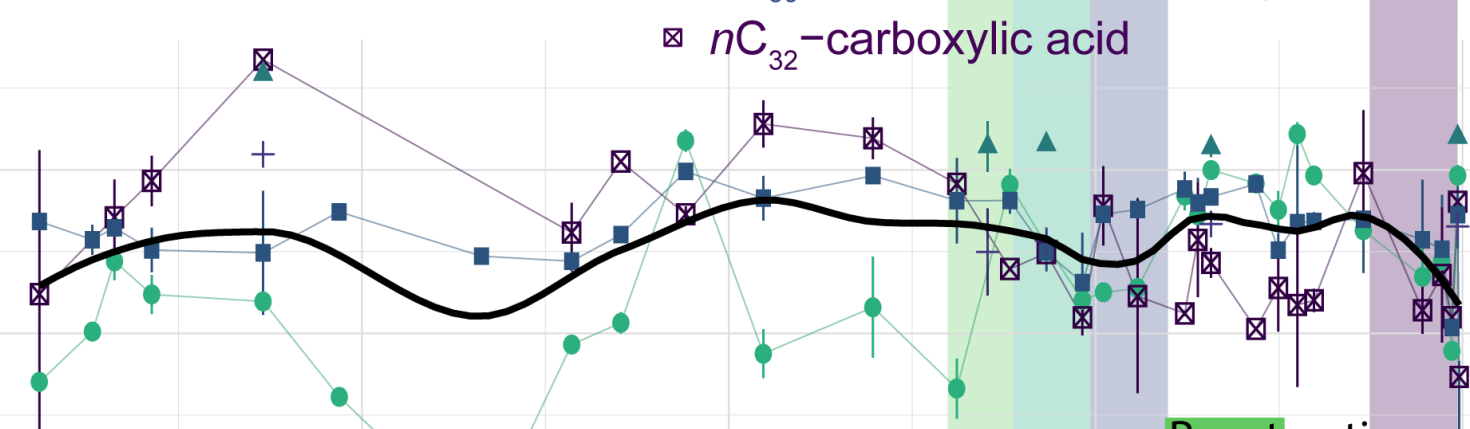

Renaturation Soil Erosion

C

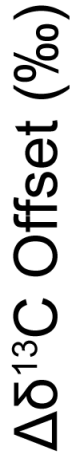

$\Delta \delta^{13} \mathrm{C}$ offset of $n$-Carboxylic Acids

0

$-2$
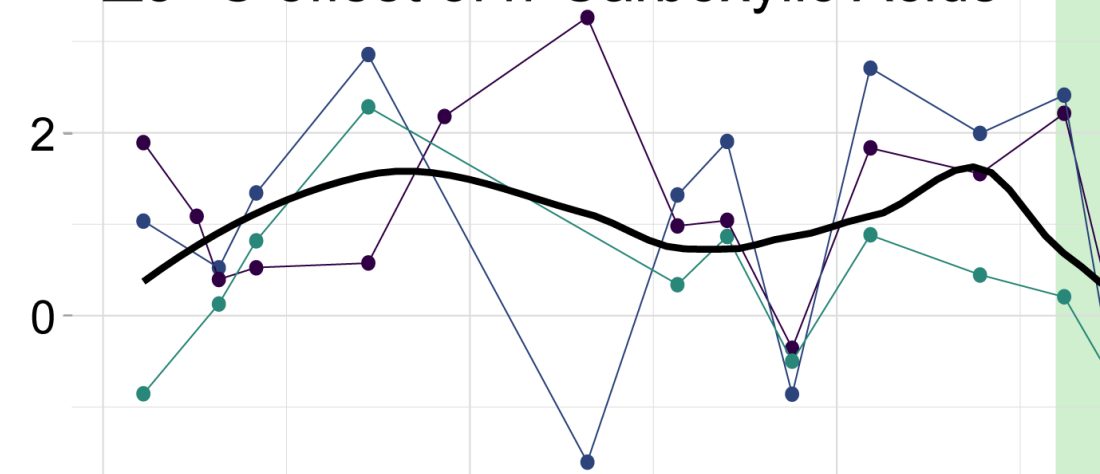

D 4000

Mean Transit Time (MTT)

$\begin{array}{ll}\widehat{D} & 2000 \\ \stackrel{E}{\Sigma} & 0\end{array}$

- Bulk Sediment (MTT ${ }_{\text {OC }}$ ) n-Alkane fractions $\left(\mathrm{MTT}_{\mathrm{Iw}}\right)$ :

- Bulk $n$-Alkanes - $n \mathrm{C}_{27+29}$

$\Delta n \mathrm{C}_{27+29+31+33}+n \mathrm{C}_{31+33}$
Neolithic Period

MP

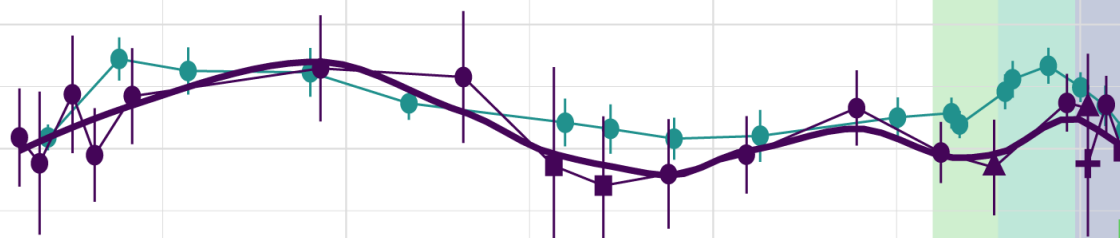

Renaturation Soil Erosion

\section{Land Clearing}

